\title{
Revealing USP7 Deubiquitinase Substrate Specificity by Unbiased Synthesis of Ubiquitin Tagged SUMO2
}

Han-Kai Jiang ${ }^{1,2,4 \dagger}$, Prashant Kurkute ${ }^{1,2,5 \dagger}$, Chien-Lung Li ${ }^{1,3}$, Yi-Hui Wang ${ }^{1}$, Pei-Jung Chen ${ }^{1,3}$, Shu-Yu Lin ${ }^{1}$, Yane-Shih Wang ${ }^{1,2,3^{*}}$

${ }^{1}$ Institute of Biological Chemistry, Academia Sinica, Taipei 11529, Taiwan

${ }^{2}$ Chemical Biology and Molecular Biophysics Program, Taiwan International Graduate Program, Academia Sinica, Taipei 11529, Taiwan

3 Institute of Biochemical Sciences, National Taiwan University, Taipei 10617, Taiwan

${ }^{4}$ Department of Chemistry, National Tsing Hua University, Hsinchu 30044, Taiwan

${ }^{5}$ Department of Chemistry, National Taiwan University, Taipei 10617, Taiwan

Email: yaneshihwang@gate.sinica.edu.tw 


\section{Supporting Information}

\section{Table of contents}

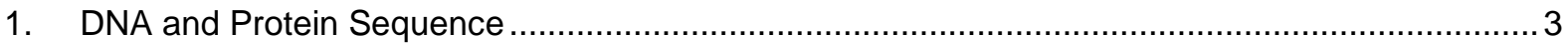

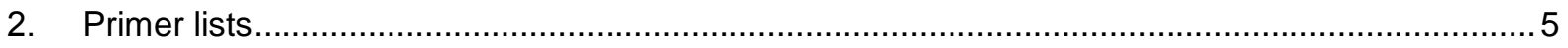

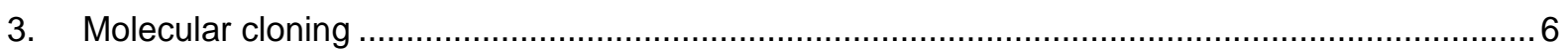

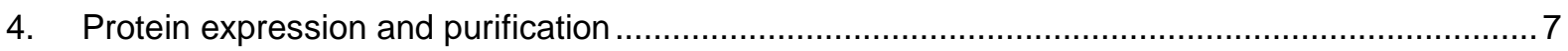

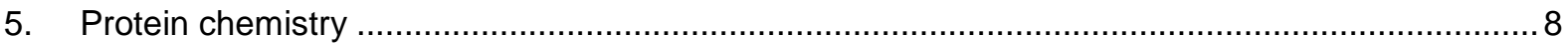

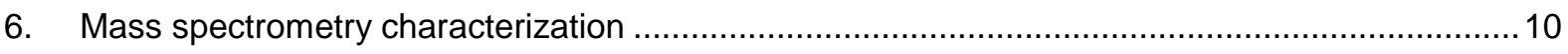

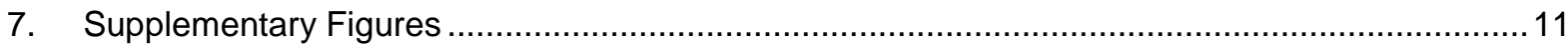




\section{DNA and Protein Sequence}

MmPyIRS:

atggataaaaaaccactaaacactctgatatctgcaaccgggctctggatgtccaggaccggaacaattcataaaataaaacaccacgaag tctctcgaagcaaaatctatattgaaatggcatgcggagaccaccttgttgtaaacaactccaggagcagcaggactgcaagagcgctcagg caccacaaatacaggaagacctgcaaacgctgcagggtttcggatgaggatctcaataagttcctcacaaaggcaaacgaagaccagac aagcgtaaaagtcaaggtcgtttctgcccctaccagaacgaaaaaggcaatgccaaaatccgttgcgagagccccgaaacctcttgagaat acagaagcggcacaggctcaaccttctggatctaaattttcacctgcgataccggtttccacccaagagtcagtttctgtcccggcatctgtttcaa catcaatatcaagcatttctacaggagcaactgcatccgcactggtaaaagggaatacgaaccccattacatccatgtctgcccctgttcaggc aagtgcccccgcacttacgaagagccagactgacaggcttgaagtcctgttaaacccaaaagatgagatttccctgaattccggcaagccttt cagggagcttgagtccgaattgctctctcgcagaaaaaaagacctgcagcagatctacgcggaagaaagggagaattatctggggaaactc gagcgtgaaattaccaggttctttgtggacaggggttttctggaaataaaatccccgatcctgatccctcttgagtatatcgaaaggatgggcatt gataatgataccgaacttcaaaacagatcttcagggttgacaagaacttctgcctgagacccatgcttgctccaaacctttacaactacctgcg caagcttgacagggccctgcctgatccaataaaaattttgaaataggcccatgctacagaaaagagtccgacggcaaagaacacctcgaa gagtttaccatgctgaacttctgccagatgggatcgggatgcacacgggaaaatcttgaaagcataattacggacttcctgaaccacctggga attgatttcaagatcgtaggcgattcctgcatggtctatggggatacccttgatgtaatgcacggagacctggaactttcctctgcagtagtcggac ccataccgcttgaccgggaatggggtattgataaaccctggataggggcaggtttcgggctcgaacgccttctaaaggttaaacacgactttaa aaatatcaagagagctgcaaggtccgagtcttactataacgggatttctaccaacctgtaa

tRNA CUA $_{\text {CUI }}$ :

ggaaacctgatcatgtagatcgaatggactctaaatccgttcagccgggttagattcccggggtttccgcca The anticodon CTA is labeled in bold.

sfGFP:

atgagcaagggcgaagaactgtttacgggcgtggtgccgattctggtggaactggatggtgatgtcaatggtcacaaattcagcgtgcgcggc gaaggtgaaggcgatgcaaccaatggtaaactgacgctgaagtttatttgcaccacgggtaaactgccggttccgtggccgaccctggtcacc acgctgacgtatggtgttcagtgtttcagtcgttacccggatcacatgaaacgccacgacttttcaagtccgcgatgccggaaggttatgtccaa gaacgtaccatctcatttaaagatgacggcacctacaaaacgcgcgccgaagtgaaattcgaaggtgatacgctggttaaccgtattgaactg aaaggcatcgattttaaggaagacggtaatattctgggccataaactggaatataacttcaattcgcacaacgtgtacatcaccgcagataagc agaagaacggtatcaaggctaacttcaagatccgccataatgtggaagatggcagcgttcaactggccgaccactatcagcaaaacacccc gattggtgatggcccggtcctgctgccggacaatcattacctgagcacgcagtctgtgctgagtaaagatccgaacgaaaagcgtgaccacat ggtcctgctggaattcgtgaccgcggccggcatcacgcacggtatggacgaactgtataaaggctcagagctccatcaccatcaccatcacta a

\section{SUMO1:}

atgagtgatcaggaagccaaaccgtctaccgaggatctgggcgataaaaaagaaggcgaatatattaaactgaaagttattggtcaggata gtagcgaaattcattttaaagttaaaatgaccacccatctgaaaaaactgaaagaatcttatgcgcagcgccagggtgtgccgatgaatagctt acgtttctgtttgaaggccagcgcattgcagataatcataccccgaaagaattaggtatggaagaagaagatgtgattgaagtgtatcaggaa cagaccggcggctaa

\section{SUMO2:}

atggcagatgaaaaaccgaaagaaggcgttaaaaccgaaaacaatgatcatattaatctgaaagttgccggccaggatggctcagtggtgc agtttaaaattaaacgtcataccccgctgagtaaactgatgaaagcctattgtgaacgccagggcctgtctatgcgccagattcgctttcgctttg atggtcagccgattaacgagaccgataccccggcacagttagagatggaagatgaagataccattgatgtgtttcagcagcagaccggtggc taa

Ub:

atgcatcatcatcatcatcatgaaaatctgtatttcagatgcagattttgtgaaaaccctgaccggcaagaccattaccttagaagttgaaccga gtgataccattgaaaatgttaaagccaaaattcaggataaagaaggcattccgccggatcagcagcgtctgattttgccggcaaacagctgg aagatggtcgcaccctgagcgattataatattcagaaagaatctaccttacatctggtgctgcgcttacgcggtggctaa 
MmPyIRS:

MDKKPLNTLISATGLWMSRTGTIHKIKHHEVSRSKIYIEMACGDHLVVNNSRSSRTARALRHHKYRKTC KRCRVSDEDLNKFLTKANEDQTSVKVKVVSAPTRTKKAMPKSVARAPKPLENTEAAQAQPSGSKFSP AIPVSTQESVSVPASVSTSISSISTGATASALVKGNTNPITSMSAPVQASAPALTKSQTDRLEVLLNPKD EISLNSGKPFRELESELLSRRKKDLQQIYAEERENYLGKLEREITRFFVDRGFLEIKSPILIPLEYIERMGI DNDTELSKQIFRVDKNFCLRPMLAPNLYNYLRKLDRALPDPIKIFEIGPCYRKESDGKEHLEEFTMLNF CQMGSGCTRENLESIITDFLNHLGIDFKIVGDSCMVYGDTLDVMHGDLELSSAVVGPIPLDREWGIDK PWIGAGFGLERLLKVKHDFKNIKRAARSESYYNGISTNL

sfGFP:

MSKGEELFTGVVPILVELDGDVNGHKFSVRGEGEGDATNGKLTLKFICTTGKLPVPWPTLVTTLTYGV QCFSRYPDHMKRHDFFKSAMPEGYVQERTISFKDDGTYKTRAEVKFEGDTLVNRIELKGIDFKEDGNI LGHKLEYNFNSHNVYITADKQKNGIKANFKIRHNVEDGSVQLADHYQQNTPIGDGPVLLPDNHYLSTQ SVLSKDPNEKRDHMVLLEFVTAAGITHGMDELYKGSELHHHHHH

SUMO1:

MSDQEAKPSTEDLGDKKEGEYIKLKVIGQDSSEIHFKVKMTTHLKKLKESYAQRQGVPMNSLRFLFEG QRIADNHTPKELGMEEEDVIEVYQEQTGG

SUMO2:

MADEKPKEGVKTENNDHINLKVAGQDGSVVQFKIKRHTPLSKLMKAYCERQGLSMRQIRFRFDGQPI NETDTPAQLEMEDEDTIDVFQQQTGG

Ub:

MHHHHHHENLYFQMQIFVKTLTGKTITLEVEPSDTIENVKAKIQDKEGIPPDQQRLIFAGKQLEDGRTL SDYNIQKESTLHLVLRLRGG 


\section{Primer list}

\begin{tabular}{|c|c|}
\hline Primers & Primer sequence $5^{\prime} \rightarrow 3^{\prime}$ \\
\hline His6X-sfGFP-Ndel-F1 & GAGATATACATATGCATCATCATCATCATCATAGCAAGGG \\
\hline SUMO2-K5-F2 & CAGATGGCAGATGAATAGCCGAAAGAAGGCGTTAAAAC \\
\hline SUMO2-K5-R1 & GCCTTCTTTCGGCTATTCATCTGCCATCTGAAAATACAG \\
\hline SUMO2-K7-F2 & GATGAAAAACCGTAGGAAGGCGTTAAAACCGAAAACAATG \\
\hline SUMO2-K7-R1 & GTTTTAACGCCTTCCTACGGTTTTTCATCTGCCATCTG \\
\hline SUMO2-K11-F2 & CCGAAAGAAGGCGTTTAGACCGAAAACAATGATCATATTAATC \\
\hline SUMO2-K11-R1 & CATTGTTTTCGGTCTAAACGCCTTCTTTCGGTTTTTCATC \\
\hline SUMO2-K21-F2 & CCGAAAGAAGGCGTTTAGACCGAAAACAATGATCATATTAATC \\
\hline SUMO2-K21-R1 & CTGGCCGGCAACCTACAGATTAATATGATCATTGTTTTCG \\
\hline SUMO2-K33-F2 & GTGGTGCAGTTTTAGATTAAACGTCATACCCCGCTGAG \\
\hline SUMO2-K33-R1 & GTATGACGTTTAATCTAAAACTGCACCACTGAGCCATCCTG \\
\hline SUMO2-K35-F2 & GCAGTTTAAAATTTAGCGTCATACCCCGCTGAGTAAACTGATG \\
\hline SUMO2-K35-R1 & CAGCGGGGTATGACGCTAAATTTTAAACTGCACCACTGAG \\
\hline SUMO2-K42-F2 & CCCCGCTGAGTAAACTGATGTAGGCCTATTGTGAACG \\
\hline SUMO2-K42-R1 & CAATAGGCTTTCATCAGCTAACTCAGCGGGGTATGACG \\
\hline SUMO2-K45-F2 & GAGTAAACTGATGTAGGCCTATTGTGAACGCCAGGGC \\
\hline SUMO2-K45-R1 & CGTTCACAATAGGCCTACATCAGTTTACTCAGCGGGG \\
\hline SUMO2-Sacl-R2 & GGTGATGGAGCTCTTAGCCACCGGTCTGCTG \\
\hline TEV-SUMO2-R1 & TTCATCTGCCATCTGAAAATACAGATTTTCTGAGCC \\
\hline TEV-SUMO2-F2 & CTGTATTTTCAGATGGCAGATGAAAAACCGAAAGAAG \\
\hline TEV-SUMO1-R1 & CCTGATCACTCATCTGAAAATACAGATTTTCTGAGCC \\
\hline TEV-SUMO1-F2 & CTGTATTTTCAGATGAGTGATCAGGAAGCCAAACCG \\
\hline SUMO1-Sacl-R & GGTGATGGAGCTCTTAGCCGCCGGTCTGTTC \\
\hline SUMO1-C52A-F1 & CAGCGCCAGGGTGTGCCGATGAATAGCTTACGTTTTC \\
\hline SUMO1-C52A-R1 & GGCACACCCTGGCGCTGCGCATAAGATTCTTTCAG \\
\hline Ub-Ndel-F1 & $\begin{array}{l}\text { CATATGCATCACCATCACCATCACGAAAATCTGTATTTTTCAGATGCAG } \\
\text { ATTTTTGTG }\end{array}$ \\
\hline Ub-Sacl-R & GATGGTGATGGAGCTCTTAGCCACCGCGTAAGCGCAGCACCAG \\
\hline TEV-Ub-R1 & CAAAAATCTGCATCTGAAAATACAGATTTTCTGAGCC \\
\hline TEV-Ub-F2 & CTGTATTTTCAGATGCAGATTTTTGTGAAAACCCTGAC \\
\hline sfGFP-2TAG-Ndel-F & GATATACATATGTAGAAGGGCGAAGAACTGTTTACGGGCG \\
\hline sfGFP-Sacl-R2 & GATGGTGATGGAGCTCTGAGCCTTTATAC \\
\hline Ub-F & GATATACATATGCAGATTTTTGTGAAAACCCTGACCGGC \\
\hline Ub-XHis-R & GATGGAGCTCGCCACCCTAGCCACCGCGTAAGCGCAG \\
\hline
\end{tabular}




\section{Molecular cloning}

\section{Construction of $p E T-p y / T$}

The plasmid $p E T$-pylT was derived from the $\mathrm{pET}-22 \mathrm{~b}(+)$ plasmid harboring an ampicillin selection marker. It was purchased from Novegen. The gene of pylT with anticodon CUA was flanked by Ipp promoter at the 5'end and rrnC terminator at 3' end. It was amplified by overlap extension PCR. The same restriction site, Sphl at 5'end and 3' end were introduced in the PCR product which was subsequently digested and used to construct pET-py/T.

\section{Construction of $p C D F-N-Z R S$}

The pCDF-N-ZRS plasmid was derived from pCDF-MmPyIRS plasmid bearing Y306M/L309A/ $\mathrm{C} 348 \mathrm{~T} / \mathrm{T} 364 \mathrm{~K} / \mathrm{Y} 384 \mathrm{~F}$ mutation sites. R61K/H63Y/S193R mutations were subsequently added using overlap extension PCR. The gene of $N$-ZRS was flanked by lpp promoter at the 5' end and rrnC terminator at 3' end. The $N$-ZRS gene was double digested with restriction enzyme BamHI and Ncol, and ligated to generate $\mathrm{pCDF}-\mathrm{N}-\mathrm{ZRS}$.

\section{Construction of $p E T$-pyIT-sfGFP-SUMO1}

The plasmid $p E T$-pylT-sfGFP-SUMO1 was derived from the plasmid $p E T-p y / T_{C U A}$. The gene of codonoptimized sfGFP and SUMO1 were synthesized by MD bio, Inc. company. The gene of sfGFPSUMO1 was flanked by a TEV protease cleavage site between SfGFP and SUMO1. The codon of cysteine at position 52 was mutated to alanine using overlap extension PCR. The gene was digested with restriction enzymes $\mathrm{Ndel}$ and Sacl, and ligated to generate different pET-py/T-sfGFP-SUMO2 variants. The gene is under the control of the T7 promoter and T7 terminator.

\section{Construction of pET-pyIT-sfGFP-SUMO2-KXTAG}

The plasmid pET-pyIT-sfGFP-SUMO2-KxTAG was derived from the plasmid pET-pylTCUA. The gene of codon-optimized SfGFP and SUMO2 were synthesized by MD bio, Inc. company. The gene of sfGFP-SUMO2-KxTAG was flanked by a TEV protease cleavage site between sfGFP and SUMO2KXTAG. $x$ represents the position of lysine in the SUMO2 gene. The SUMO2 gene bearing TAG at 8 lysine positions were amplified by overlap extension PCR individually. The gene was digested with restriction enzymes Ndel and Sacl, and ligated to generate different pET-pylT-sfGFP-SUMO2 variants. The gene is under the control of T7 promoter and T7 terminator.

\section{Construction of $p E T-p y / T-U b$ and $p E T-p y / T-U b 77 T A G$}

The plasmid $\mathrm{pET}$-pylT-Ub and pET-pylT-Ub77TAG were derived from the plasmid $\mathrm{pET}$-py/T CUA. The gene of optimized Ub was synthesized by MD bio, Inc. company. The gene of $U b$ construct is composed of the N-terminal hexahistidine following by TEV protease cleavage site. The gene of Ub77TAG is composed of an amber codon at position 77 following by a C-terminal hexahistidine. Both genes were amplified by overlap extension PCR. The two restriction sites Ndel and Sacl were used to digest the target genes. The double digested genes were ligated to generate $\mathrm{pET}-\mathrm{py} / \mathrm{T}-\mathrm{Ub}$ and pET-pylT-Ub77TAG, respectively. The genes are under the control of T7 promoter and T7 terminator. 


\section{Protein expression and purification}

\section{Expression and purification of SfGFP-SUMO1}

The plasmid was chemically transformed into E. coli BL21 (DE3) for protein expression. A single colony was cultured in $10 \mathrm{~mL} \mathrm{LB}$ medium with the $100 \mu \mathrm{g} / \mathrm{mL}$ ampicillin and incubated at $37^{\circ} \mathrm{C}$ overnight. $10 \mathrm{~mL}$ bacteria liquid was transferred to $1 \mathrm{~L}$ fresh LB medium with an appropriate antibiotic and incubated at $37^{\circ} \mathrm{C}$ until $\mathrm{OD}_{600}$ reached $0.6-0.8$. Protein was expressed in the presence of $1 \mathrm{mM}$ IPTG at $37^{\circ} \mathrm{C}$ for $12 \mathrm{~h}$. The bacteria culture was harvested by centrifugation at $6000 \times g$ for 20 minutes at $4{ }^{\circ} \mathrm{C}$ and the supernatant was discarded. The pellet was resuspended in lysis buffer $(1 \mathrm{X}$ PBS, pH 8.0). The pellet was resuspended and sonicated on an ice bath for 10 minutes. The supernatant was collected after centrifuged at $20000 \times g$ for 60 minutes at $4{ }^{\circ} \mathrm{C}$. The recombinant protein was purified by Ni²+-NTA chromatography (Roche). 10 column volume of lysis buffer and 5 column volume of washing buffer (1X PBS, $5 \mathrm{mM}$ imidazole, $\mathrm{pH} 8.0$ ) was used to wash out the proteins bound non-specifically. 5 column volume of elution buffer (1X PBS, $200 \mathrm{mM}$ imidazole, $\mathrm{pH}$ 8.0) was used to elute the target protein. The eluted fraction was changed to storage buffer $(200 \mathrm{mM}$ $\mathrm{NaCl}$, and $50 \mathrm{mM}$ Tris, pH8.0) by dialysis, and concentrated by Amicon Ultra-Centrifugal Filter-10,000 MWCO (Millipore). The SUMO1 protein was collected using Ni ${ }^{2+}$-NTA resin to remove sfGFP with Nterminal hexahistidine after the treatment of TEV protease at $4^{\circ} \mathrm{C}$ overnight.

\section{Expression and purification of SUMO1-activating enzyme (SAE2/SAE1)}

The pGEX-SAE2/SAE1 was obtained from Prof. Hsiu-Ming Shih lab (Institute of Biomedical Sciences, Academia Sinica). The N-terminal GST tag was replaced with a hexahistidine tag using PCR. pGEXSAE2/SAE1 was expressed and purified from E. coli BL21-CodonPlus (DE3)-RIPL cells. A single colony was cultured in $100 \mathrm{~mL}$ LB medium with the $100 \mu \mathrm{g} / \mathrm{mL}$ ampicillin and $34 \mu \mathrm{g} / \mathrm{mL}$ chloramphenicol incubated at $37^{\circ} \mathrm{C}$ overnight. And the culture was inoculated into $12 \mathrm{~L} \mathrm{LB}$ medium and incubated at $37^{\circ} \mathrm{C}$ until $\mathrm{OD}_{600}$ reached 0.6-0.8. Protein was expressed using $0.5 \mathrm{mM}$ IPTG and incubated at $16^{\circ} \mathrm{C}$ for $16 \mathrm{~h}$. The cells were pelleted, resuspended in $150 \mathrm{~mL}$ of lysis buffer $(50 \mathrm{mM}$ Tris- $\mathrm{HCl}, 150 \mathrm{mM} \mathrm{NaCl}, 20 \mathrm{mM}$ imidazole, $0.1 \%$ Triton X-100, pH 8.0, $0.5 \mathrm{mM} \mathrm{DTT}$ ), and sonicated for 10 minutes on an ice bath. The lysate was collected after centrifuged at $20000 \times g$ for 40 minutes at $4{ }^{\circ} \mathrm{C}$. The recombinant protein was purified by $\mathrm{Ni}^{2+}-\mathrm{NTA}$ column and washed with 10 column volume of lysis buffer ( $50 \mathrm{mM}$ Tris- $\mathrm{HCl}, 500 \mathrm{mM} \mathrm{NaCl}, 20 \mathrm{mM}$ imidazole, $\mathrm{pH}$ 8.0). Protein was eluted using 12 column volume of elution buffer $(50 \mathrm{mM}$ Tris-HCl, $500 \mathrm{mM} \mathrm{NaCl}, 250 \mathrm{mM}$ imidazole, $\mathrm{pH}$ 7.8) then dialyzed to $50 \mathrm{mM}$ Tris- $\mathrm{HCl}, 25 \mathrm{mM} \mathrm{NaCl}, \mathrm{pH}$ 8.0, $0.5 \mathrm{mM}$ DTT for anion-exchange chromatography. Finally, the recombinant protein was purified by gel filtration chromatography (HiLoad 16/600 superdex 200 pg, GE Healthare) with storage buffer ( $150 \mathrm{mM} \mathrm{NaCl}, 20 \mathrm{mM}$ HEPES, $\mathrm{pH}$ 8.0), and concentrated by Amicon Ultra-Centrifugal Filter -30,000 MWCO (Millipore).

\section{Expression and purification of $U b$}

The plasmid was chemically transformed into E. coli BL21 (DE3) for protein expression. A single colony was cultured in $5 \mathrm{~mL}$ LB medium with the $100 \mu \mathrm{g} / \mathrm{ml}$ ampicillin and incubated at $37^{\circ} \mathrm{C}$ overnight. $1 \mathrm{~mL}$ bacterial liquid was transferred to $100 \mathrm{~mL}$ fresh LB medium with appropriate antibiotics and incubated at $37^{\circ} \mathrm{C}$ until $\mathrm{OD}_{600}$ reached 0.4-0.6. Protein was expressed by adding 1 $\mathrm{mM} \mathrm{IPTG}$ at $25^{\circ} \mathrm{C}$ for $12 \mathrm{~h}$. The bacteria culture was harvested by centrifugation at $10000 \times g$ for 10 minutes at $4{ }^{\circ} \mathrm{C}$ and the supernatant was discarded. The pellet was resuspended in lysis buffer $(300$ $\mathrm{mM} \mathrm{NaCl}, 20 \mathrm{mM} \mathrm{KH}_{2} \mathrm{PO}_{4}, 0.5 \%$ Triton X-100, pH 8.0) and sonicated on an ice bath for 10 minutes. The supernatant was collected after centrifuged at $20000 \times g$ for 50 minutes at $4{ }^{\circ} \mathrm{C}$. The recombinant protein was purified by $\mathrm{Ni}^{2+}$-NTA chromatography (Roche). 25 column volume of lysis buffer and 10 column volume of washing buffer ( $300 \mathrm{mM} \mathrm{NaCl}, 20 \mathrm{mM} \mathrm{KH}_{2} \mathrm{PO}_{4}, 10 \mathrm{mM}$ imidazole, $\mathrm{pH}$ 8.0) was used to wash out the non-specific binding proteins. 5 column volume of elution buffer ( $300 \mathrm{mM} \mathrm{NaCl}$, $20 \mathrm{mM} \mathrm{KH}_{2} \mathrm{PO}_{4}$ and $250 \mathrm{mM}$ imidazole, $\mathrm{pH} \mathrm{8.0)}$ was used to elute the target protein. The eluted fraction was changed to storage buffer (20 mM HEPES, and $100 \mathrm{mM} \mathrm{NaCl}, \mathrm{pH} 8.0)$ by dialysis, and concentrated by Amicon Ultra-Centrifugal Filter-3,000 MWCO (Millipore).

\section{Expression and purification of mouse ubiquitin-activating enzyme (mE1)}

The pET28-mE1 plasmid was a gift from Jorge Eduardo Azevedo (Addgene plasmid \# 32534; http://n2t.net/addgene: 32534 ; RRID:Addgene_32534). mE1 was expressed and purified from E. coli BL21-CodonPlus (DE3)-RIPL cells. A single colony was cultured in $100 \mathrm{~mL}$ LB medium with the 100 $\mu \mathrm{g} / \mathrm{mL}$ kanamycin and $34 \mu \mathrm{g} / \mathrm{mL}$ chloramphenicol incubated at $37^{\circ} \mathrm{C}$ overnight. And the culture was 
inoculated into $12 \mathrm{~L} \mathrm{LB}$ medium and incubated at $37^{\circ} \mathrm{C}$ until $\mathrm{OD}_{600}$ reached $0.6-0.8$. Protein was expressed using $0.6 \mathrm{mM} \mathrm{IPTG}$ and incubated at $16^{\circ} \mathrm{C}$ for $16 \mathrm{~h}$. The cells were pelleted, resuspended in $150 \mathrm{~mL}$ of lysis buffer (50 mM HEPES, $150 \mathrm{mM} \mathrm{NaCl}, 0.1 \%$ Triton X-100, pH 8.0, $0.2 \mathrm{mM}$ DTT), and sonicated for 10 minutes on an ice bath. The lysate was collected after centrifuged at $20000 \times \mathrm{g}$ for 60 minutes at $4{ }^{\circ} \mathrm{C}$. The recombinant protein was purified by $\mathrm{Ni}^{2+}-\mathrm{NTA}$ column and washed with 10 column volume of lysis buffer (50 mM HEPES, $500 \mathrm{mM} \mathrm{NaCl}, 10 \mathrm{mM}$ imidazole, $\mathrm{pH}$ 7.8). Protein was eluted using 12 column volume of elution buffer $(50 \mathrm{mM}$ HEPES, $500 \mathrm{mM} \mathrm{NaCl}, 250 \mathrm{mM}$ imidazole, $\mathrm{pH}$ 7.8) then dialyzed to $50 \mathrm{mM}$ Tris- $\mathrm{HCl}, 25 \mathrm{mM} \mathrm{NaCl}, \mathrm{pH}$ 8.0, $0.2 \mathrm{mM}$ DTT for anion-exchange chromatography. Finally, the recombinant protein was purified by gel filtration chromatography (HiLoad 16/600 superdex 200 pg, GE Healthare) with storage buffer ( $150 \mathrm{mM} \mathrm{NaCl}, 20 \mathrm{mM} \mathrm{HEPES}$, pH 8.0), and concentrated by Amicon Ultra-Centrifugal Filter-30,000 MWCO (Millipore).

\section{Expression and purification of sfGFP-SUMO2-KxSeCbzK}

The plasmid pET-pylT-sfGFP-SUMO2-KxTAG was co-transformed with pCDF-N-ZRS into E. coli BL21 (DE3) for protein expression. A single colony was cultured in $5 \mathrm{~mL}$ LB medium with $100 \mu \mathrm{g} / \mathrm{mL}$ ampicillin and $100 \mu \mathrm{g} / \mathrm{mL}$ streptomycin then incubated at $37^{\circ} \mathrm{C}$ overnight. $1 \mathrm{~mL}$ bacterial liquid was transferred to $100 \mathrm{~mL}$ fresh LB medium with appropriate antibiotics and incubated at $37^{\circ} \mathrm{C}$ until $\mathrm{OD}_{600}$ reached 0.8-1.0. Protein was expressed in the presence of $1 \mathrm{mM} \mathrm{SeCbzK}$ and IPTG at $37^{\circ} \mathrm{C}$ for $12 \mathrm{~h}$. The bacteria culture was harvested by centrifugation at $10000 \times g$ for 10 minutes and the supernatant was discarded. The pellet was resuspended with PBS buffer and sonicated on ice bath for 10 minutes. The supernatant was collected after centrifugation at $20000 \times g$ for 50 minutes at $4{ }^{\circ} \mathrm{C}$. The protein was purified by Ni²+-NTA chromatography (Roche). 10 column volume of lysis buffer and 5 column volume of washing buffer (PBS buffer, $5 \mathrm{mM}$ imidazole, $\mathrm{pH} 8.0$ ) was used to wash out the nonspecific binding proteins. 5 column volume of elution buffer (PBS buffer, $250 \mathrm{mM}$ imidazole, $\mathrm{pH}$ 8.0) was used to elute the target protein. The buffer of the eluted fraction was changed to $200 \mathrm{mM} \mathrm{NaCl}$, $50 \mathrm{mM}$ Tris- $\mathrm{HCl}, \mathrm{pH} 8.0$ for TEV protease cleavage. The fraction was passed through the $\mathrm{Ni}^{2+}-\mathrm{NTA}$ column to remove sfGFP.

\section{Expression and purification of $\mathrm{Ub}-77 \mathrm{Cbz} \mathrm{KOH}$}

The plasmid pET-PyIT-Ub77TAG was co-transformed with pCDF-N-ZRS into E. coli BL21(DE3) for protein expression. A single colony was cultured in $5 \mathrm{~mL} \mathrm{LB}$ medium with $100 \mu \mathrm{g} / \mathrm{mL}$ ampicillin and $100 \mu \mathrm{g} / \mathrm{mL}$ streptomycin then was incubated at $37^{\circ} \mathrm{C}$ overnight. $1 \mathrm{~mL}$ bacterial liquid was transferred to $100 \mathrm{~mL}$ fresh LB medium with $100 \mu \mathrm{g} / \mathrm{mL}$ ampicillin and $100 \mu \mathrm{g} / \mathrm{mL}$ streptomycin and incubated at $37^{\circ} \mathrm{C}$ until $\mathrm{OD}_{600}$ reached $0.8-1.0$. Protein was expressed in the presence of $1 \mathrm{mM} \mathrm{CbzKOH}$ and IPTG at $37^{\circ} \mathrm{C}$ for $12 \mathrm{~h}$. The bacteria were harvested by centrifugation at $10,000 \times \mathrm{g}$ for 10 minutes. The pellet was resuspended with lysis buffer (1xPBS, $350 \mathrm{mM} \mathrm{NaCl}$, and $20 \mathrm{mM}$ imidazole at pH 7.0) and sonicated on an ice bath for 10 minutes. The supernatant was collected after centrifugation at $20,000 \times g$ for 50 minutes at $4{ }^{\circ} \mathrm{C}$. The protein was purified by Ni²+-NTA chromatography. $50 \mu \mathrm{L}$ GE Healthcare ${ }^{\circledR}$ resin was loaded in an open column for purification. 20 column volume of lysis buffer, 10 column volume of washing buffer 1 (1XPBS, $500 \mathrm{mM} \mathrm{NaCl}$, and $20 \mathrm{mM}$ imidazole at pH7.0), and 3 column volume washing buffer 2 (1XPBS and $30 \mathrm{mM}$ imidazole at $\mathrm{pH} 7.0$ ) were used to wash out the non-specific binding protein. 5 column volume of elution buffer (1xPBS, $200 \mathrm{mM}$ imidazole at pH 7.0) was used to elute the target protein. The buffer of the eluted collection was changed to storage buffer (1xPBS at pH 7.0) by gel filtration chromatography (Superdex 75 Increase 10/300 GL, GE Healthare).

\section{Ub tagged SUMO2 dimers purification}

Reaction after dimer synthesis was quenched by the addition of excess DTT. The dimers were purified by Ni2+-NTA chromatography. 5 column volume of binding buffer (4 mM DTT, PBS buffer, pH 7.5) and 5 column volume of washing buffer (PBS buffer, $5 \mathrm{mM}$ imidazole, $\mathrm{pH} 7.5$ ) was used to wash out the non-specific binding proteins. 5 column volume of elution buffer (PBS buffer, $250 \mathrm{mM}$ imidazole, $\mathrm{pH}$ 7.5) was used to elute the target dimers. The dimers were further purified by size exclusion chromatography (Superdex S75 increase 10/300 GL) using 4 mM DTT, PBS buffer, pH 7.5, and concentrated by Amicon Ultra-Centrifugal Filter-10,000 MWCO (Millipore). The dimers were quantified by western blot.

\section{Protein chemistry}

Preparation of SUMO1-cysteamine 
$50 \mathrm{~mL}$ of a $1 \mu \mathrm{M}$ SUMO E1, $50 \mu \mathrm{M}$ SUMO1, $2 \mathrm{mM}$ ATP, $2 \mathrm{mM}$ DTT, $5 \mathrm{mM} \mathrm{MgCl} 2$ and $5 \mathrm{mM}$ cysteamine were mixed with the buffer containing $100 \mathrm{mM} \mathrm{NaCl}, 20 \mathrm{mM} \mathrm{HEPES}, \mathrm{pH} 8.0$ at $4^{\circ} \mathrm{C}$ for 12 h. The SUMO1-cysteamine was purified by size-exclusion chromatography (HiLoad 16/600 superdex $75 \mathrm{pg}$, GE Healthare) with storage buffer (200 mM NaCl, $50 \mathrm{mM}$ Tris, pH 8.0), and concentrated by Amicon Ultra- Centrifugal Filter-3,000 MWCO (Millipore). The concentrated protein was frozen in liquid nitrogen then stored at $-80^{\circ} \mathrm{C}$ for preservation.

\section{Selenoxide $\beta$-elimination of sfGFP-S2SeCbzK}

$30 \mu \mathrm{M}$ sfGFP-S2SeCbzK was incubated with 200 equivalent $\mathrm{H}_{2} \mathrm{O}_{2}$ in $25 \mu \mathrm{L}$ (final volume) of a PBS buffer pH 8.0 at $37^{\circ} \mathrm{C}$ for 2 h. 200 equivalent $\mathrm{Na}_{2} \mathrm{~S}_{2} \mathrm{O}_{3}$ was used to quench the reaction. The buffer of the fraction then dialyzed with storage buffer $(200 \mathrm{mM} \mathrm{NaCl}, 50 \mathrm{mM}$ Tris, $\mathrm{pH}$ 8.0) and concentrated by Amicon Ultra- Centrifugal Filter-10,000 MWCO (Millipore). The concentrated protein was frozen in liquid nitrogen and stored at $-80^{\circ} \mathrm{C}$ for preservation.

\section{SUMO1 tagged sfGFP synthesis}

SUMO1-SH was incubated for $2 \mathrm{~h}$ at room temperature with TCEP reducing gel (Pierce, Thermo Scientific). This slurry was centrifuged in the spin-cup column to remove the reducing gel. $300 \mu \mathrm{M}$ SUMO1-SH monomer was then reacted with $10 \mu \mathrm{M}$ sfGFP-S2Dha at $37^{\circ} \mathrm{C}$, in $50 \mathrm{mM}$ Tris, $200 \mathrm{mM}$ $\mathrm{NaCl}, \mathrm{pH} 8.8$ reaction buffer for $20 \mathrm{~h}$.

\section{Preparation of Ub-cysteamine by Ub E1}

$50 \mathrm{~mL}$ of a $1 \mu \mathrm{M} \mathrm{E} 1,50 \mu \mathrm{M}$ Ub, $2 \mathrm{mM}$ ATP, $2 \mathrm{mM}$ DTT, $5 \mathrm{mM} \mathrm{MgCl} 2$ and $5 \mathrm{mM}$ cysteamine were mixed with the buffer containing $100 \mathrm{mM} \mathrm{NaCl}, 20 \mathrm{mM} \mathrm{HEPES}, \mathrm{pH} 8.0$ at $4{ }^{\circ} \mathrm{C}$ for $12 \mathrm{~h}$. The Ubcysteamine was purified by size-exclusion chromatography (HiLoad 16/600 superdex $75 \mathrm{pg}$, GE Healthare) with storage buffer ( $200 \mathrm{mM} \mathrm{NaCl}, 50 \mathrm{mM}$ Tris, $\mathrm{pH} 8.0)$, and concentrated by Amicon Ultra- Centrifugal Filter-3,000 MWCO (Millipore). The concentrated protein was frozen in liquid nitrogen then stored at $-80^{\circ} \mathrm{C}$ for preservation.

\section{Preparation of Ub-cysteamine by hydrazide-based native chemical ligation}

$100 \mu \mathrm{L} \mathrm{Ub-77CbzKOH}$ protein $(0.5 \mathrm{mg} / \mathrm{mL})$ was dialyzed to buffer $\mathrm{A}(0.1 \mathrm{M} \mathrm{NaCl}, 0.1 \mathrm{M}$ sodium phosphate buffer at pH 7.0) in dialysis membrane MWCO 3,000 Da. Hydrazine $50 \mu \mathrm{L}$ of a $12 \%$ stock solution in buffer $\mathrm{A}$ was added. The reaction mixture was incubated at $500 \mathrm{rpm}, 28^{\circ} \mathrm{C}$ for $2 \mathrm{~h}$ in the thermomixer. The $\mathrm{Ub}-\mathrm{NHNH}_{2}$ protein was then buffer exchanged into buffer $\mathrm{B}(0.1 \mathrm{M} \mathrm{NaCl}, 0.2 \mathrm{M}$ sodium phosphate buffer at $\mathrm{pH} 4$ ) by Amicon® Ultra $0.5 \mathrm{~mL}$ Centrifugal Filters ( $3 \mathrm{kDa}$ ). To synthesize $\mathrm{Ub}-\mathrm{SH}, 50 \mu \mathrm{L} \mathrm{Ub}-\mathrm{NHNH}_{2}$ protein $(0.5 \mathrm{mg} / \mathrm{mL})$ in buffer $\mathrm{B}$ was cooled to $0{ }^{\circ} \mathrm{C}$ on ice bath. Then, sodium nitrite $\left(\mathrm{NaNO}_{2}\right) 8 \mu \mathrm{L}$ of $0.2 \mathrm{M}$ stock solution in $\mathrm{ddH}_{2} \mathrm{O}$ was added at $0{ }^{\circ} \mathrm{C}$ for diazotization. The reaction mixture was gently stirred for 10 mins at $0{ }^{\circ} \mathrm{C}$. Sequentially, $50 \mu \mathrm{L}$ cysteamine solution $(0.2 \mathrm{M}$ cysteamine, $0.1 \mathrm{M} \mathrm{NaCl}, 0.2 \mathrm{M}$ sodium phosphate buffer at $\mathrm{pH}$ 7) was added to the diazotization reaction mixture and incubating at $500 \mathrm{rpm}, 28{ }^{\circ} \mathrm{C}$ for $40 \mathrm{mins}$. The proteins were finally buffer exchanged to buffer A with $1 \mathrm{mM}$ DTT. The molecular weight of $\mathrm{Ub}-\mathrm{NHNH}_{2}$ and $\mathrm{Ub}-\mathrm{SH}$ were analyzed by MADI-TOF-MS spectrometry.

\section{Selenoxide $\beta$-elimination of SUMO2-KxSeCbzK}

$30 \mu \mathrm{M}$ SUMO2-KxSeCbzK was incubated with 200 equivalent $\mathrm{H}_{2} \mathrm{O}_{2}$ in $25 \mu \mathrm{L}$ (final volume) of a PBS buffer $\mathrm{pH} 8.0$ at $37^{\circ} \mathrm{C}$ for $2 \mathrm{~h}$. 200 equivalent $\mathrm{Na}_{2} \mathrm{~S}_{2} \mathrm{O}_{3}$ was used to quench the reaction. The buffer of the fraction then dialyzed with storage buffer $(200 \mathrm{mM} \mathrm{NaCl}, 50 \mathrm{mM}$ Tris, $\mathrm{pH}$ 8.0) and concentrated by Amicon Ultra- Centrifugal Filter-3,000 MWCO (Millipore). The concentrated protein was frozen in liquid nitrogen and stored at $-80^{\circ} \mathrm{C}$ for preservation.

\section{Ub tagged SUMO2 dimer synthesis}

$\mathrm{Ub}-\mathrm{SH}$ was incubated for $2 \mathrm{~h}$ at room temperature with TCEP reducing gel (Pierce, Thermo Scientific). This slurry was centrifuged in the spin-cup column to remove the reducing gel. $180 \mu \mathrm{M} \mathrm{Ub-}$ $\mathrm{SH}$ monomer was then reacted with $9 \mu \mathrm{M}$ SUMO2-KxDha at $25^{\circ} \mathrm{C}$, in $50 \mathrm{mM}$ Tris, $200 \mathrm{mM} \mathrm{NaCl}, \mathrm{pH}$ 8.8 reaction buffer for $20 \mathrm{~h}$.

Ub homodimers and Ub tagged SUMO2 dimers cleavage assay 
$32 \mu \mathrm{L}$ reaction was set by mixing $16 \mu \mathrm{L} 0.16 \mu \mathrm{M}$ USP7FL or USP7CD and $16 \mu \mathrm{L}$ of $1.6 \mu \mathrm{M}$ Ub dimer or Ub tagged SUMO2 dimers. 1X PBS, $5 \mathrm{mM}$ DTT, $0.05 \mathrm{mg} / \mathrm{mL}$ BSA was used as reaction buffer. Reactions were maintained at $37^{\circ} \mathrm{C}$. Aliquots of $10 \mu \mathrm{L}$ were taken at the indicated time point and reactions were quenched by mixing with $5 X$ SDS sample buffer. Samples were run in SDS-PAGE followed by silver stain or western blot. All eight homodimeric Ub chain types, USP7FL and USP7CD were purchased from Boston Biochem.

\section{Western blotting}

All of the western blots in this study were performed using the Trans-Blot Turbo RTA transfer kit (BioRad). The following antibodies were used for immunoblotting: Anti-SUMO2/3, clone 8A2 (LTK BioLaboratories; custom antibody; 1:1000 dilution), and HRP-conjugated secondary antibody (Cell Signaling Technology; product no. 7076P2; 1:5000 dilution). The WesternBright ECL HRP substrate (Advansta; catalog no. K-12045-D50) was used for visualizing the results.

\section{Mass spectrometry characterization}

In-gel digestion

After the staining procedure, gel bands were excised and cut into small pieces. Briefly, after washing the gel pieces with $50 \%$ acetonitrile/25 $\mathrm{mM} \mathrm{NH}_{4} \mathrm{HCO}_{3}$ buffer, the reduction with $50 \mathrm{mM} \mathrm{DTE} / 25 \mathrm{mM}$ $\mathrm{NH}_{4} \mathrm{HCO}_{3}$ following alkylation with $100 \mathrm{mM}$ iodoacetamide/25 mM NH $\mathrm{HCO}_{3}$ solution of proteins in gel pieces were performed. The gel pieces were washed with $50 \%$ acetonitrile/25 $\mathrm{mM} \mathrm{NH}_{4} \mathrm{HCO}_{3}$ and dried in a vacuum centrifuge before protease digestion. SUMO1-K2sfGFP protein was digested by chymotrypsin, and Ub-K11SUMO2 protein was digested by Lys-C/trypsin (Promega). A solution in 25 $\mathrm{mM} \mathrm{NH}_{4} \mathrm{HCO}_{3}$ containing 50 to $100 \mathrm{ng}$ of sequencing grade modified chymotrypsin or Lys-C/trypsin (Promega) in 50-60 $\mu \mathrm{L}$ was added and incubated with gel pieces for $12-16 \mathrm{~h}$ at $37^{\circ} \mathrm{C}$. The reaction was stopped by adding $50 \mu \mathrm{L}$ of $50 \%$ acetonitrile/ $5 \%$ formic acid solution. The digested peptides were extracted and dried before subjected to $\mathrm{C}_{18}$ zip-tipping (Merck). The eluted peptides were dried and subjected to LC-ESI-MS/MS Analysis.

\section{LC-ESI-MS/MS analysis}

Shotgun proteomic identifications - NanoLC-nanoESI-MS/MS analysis was performed on a nanoAcquity system (Waters, Milford, MA) connected to the LTQ Orbitrap Velos hybrid mass spectrometer (Thermo Electron, Bremen, Germany) equipped with a Nanospray Flex interface. Peptide mixtures were loaded onto a $75 \mu \mathrm{m}$ ID, $25 \mathrm{~cm}$ length C18 BEH column (Waters, Milford, MA) packed with $1.7 \mu \mathrm{m}$ particles with a pore with of $130 \AA$ and were separated using a segmented gradient in $60 \mathrm{~min}$ from $5 \%$ to $35 \%$ solvent B (acetonitrile with $0.1 \%$ formic acid) at a flow rate of 300 $\mathrm{nL} / \mathrm{min}$ and a column temperature of $35^{\circ} \mathrm{C}$. Solvent $\mathrm{A}$ was $0.1 \%$ formic acid in water. The mass spectrometer was operated in the data-dependent mode. Briefly, the survey full scan MS spectrum was acquired in the orbitrap $(\mathrm{m} / \mathrm{z} 350-1600)$ with the resolution set to $60 \mathrm{~K}$ at $\mathrm{m} / \mathrm{z} 400$ and automatic gain control (AGC) target at $10^{6}$. The 10 most intense ions were sequentially isolated for HCD MS/MS fragmentation and detection in the orbitrap with previously selected ions dynamically excluded for 60 s. For MS/MS, we used a resolution of 7500 , an isolation window of $2 \mathrm{~m} / \mathrm{z}$, and a target value of 50000 ions, with maximum accumulation times of $250 \mathrm{~ms}$. Fragmentation was performed with a normalized collision energy of $35 \%$ and an activation time of $0.1 \mathrm{~ms}$. lons with singly and unrecognized charge states were also excluded.

\section{The intact protein molecular weight characterization}

The pure protein was diluted with $50 \%$ acetonitrile and $1 \%$ formic acid. An aliquot corresponding to one pmol of the pure protein was injected via an ESI source (Waters LockSpray Exact Mass Ionization Source) with a syringe pump (Harvard Apparatus, MA) and held a flow rate of $5 \mu \mathrm{l} / \mathrm{min}$ throughout the analysis. The mass of intact proteins was determined using Waters Synapt G2 HDMS mass spectrometer (Waters, Milford, MA). The acquired spectra were deconvoluted to a single-charge state using MaxEnt1 algorithm of the MassLynx 4.1 software (Waters). 


\section{Supplementary Figures}

(A)

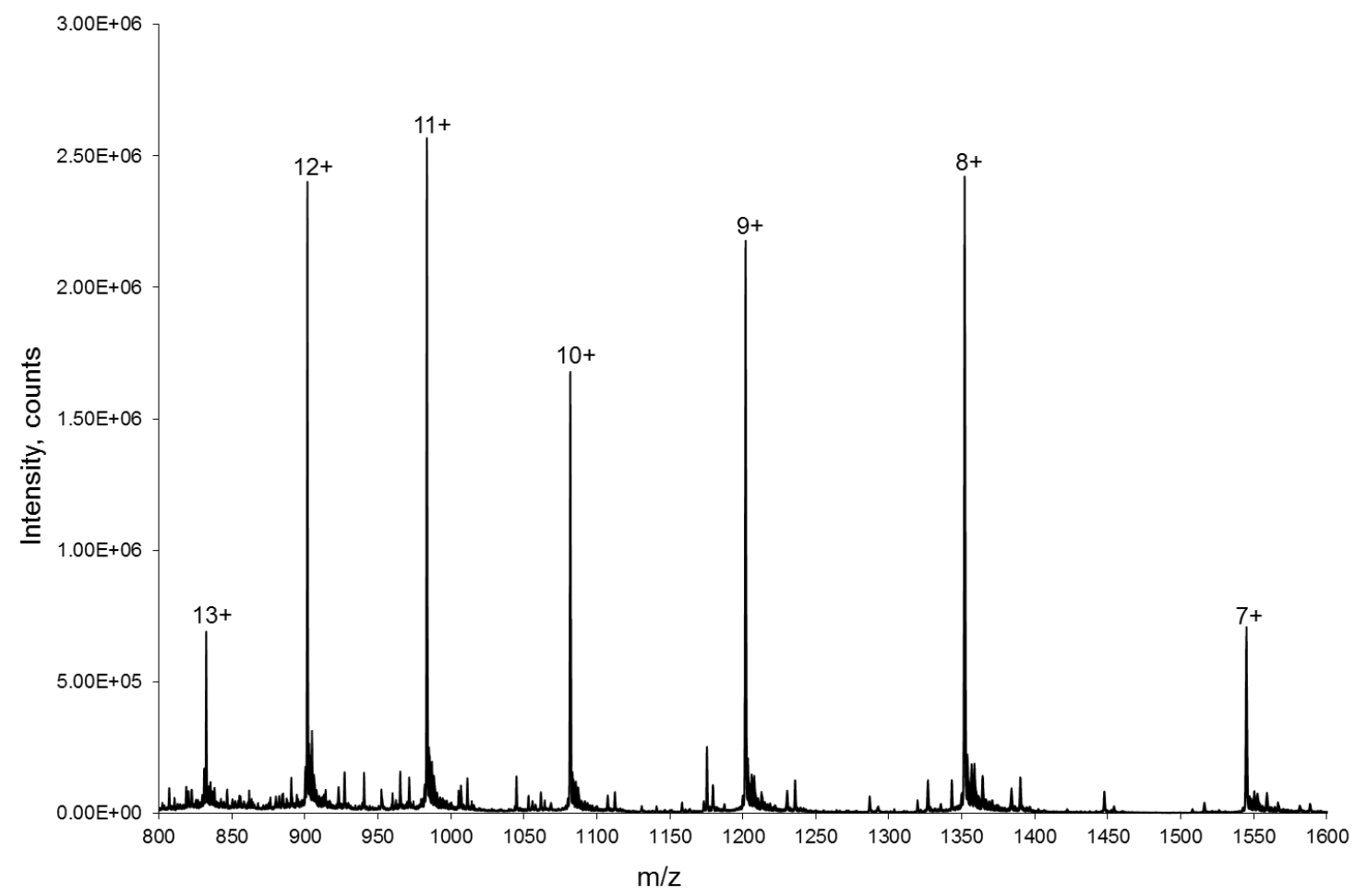

(B)

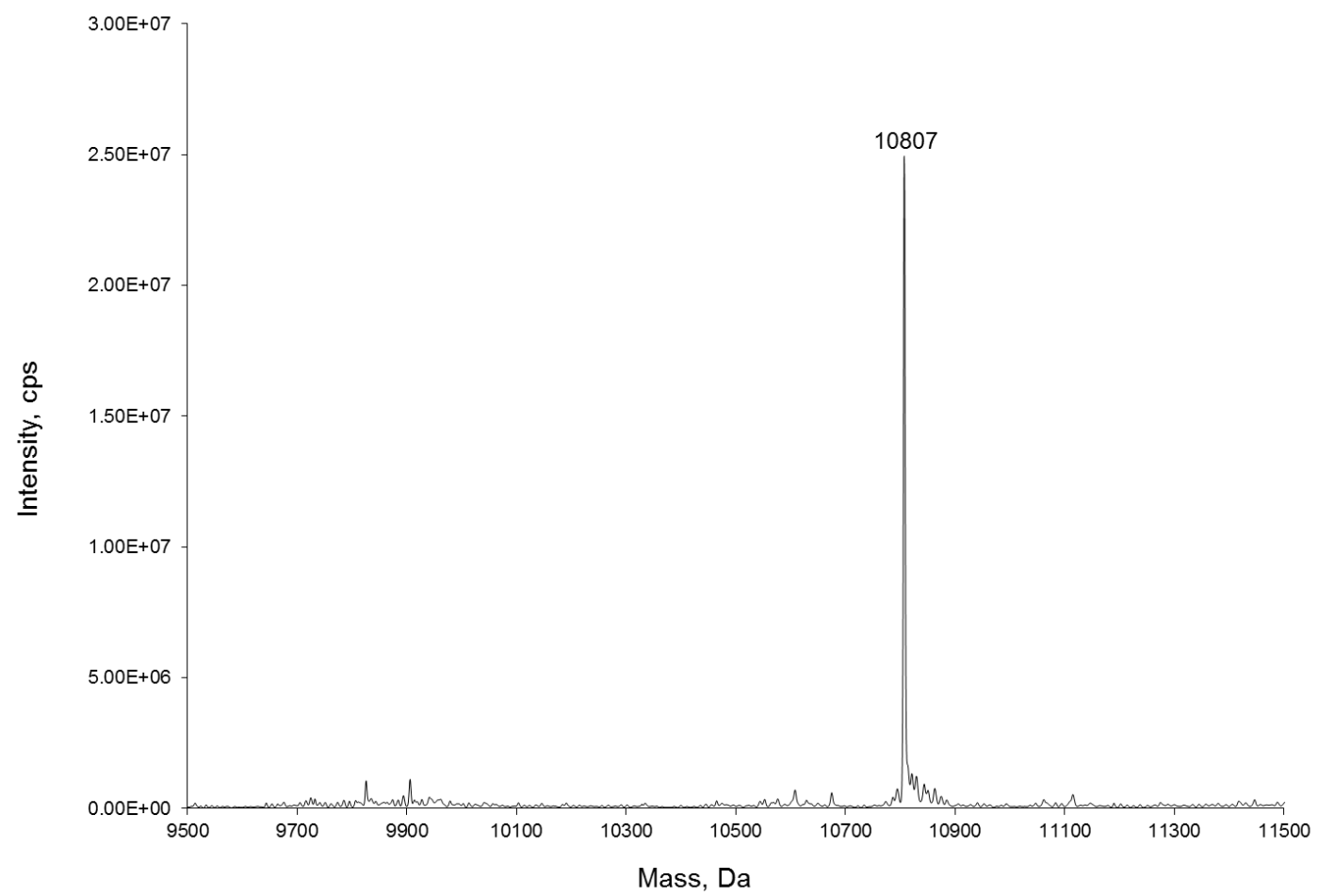

Figure S1. Molecular mass characterization of SUMO2-K5SeCbzK.

(A) ESI-MS spectrum of SUMO2-K5SeCbzK; (B) The deconvoluted ESI-MS spectrum of SUMO2K5SeCbzK. The calculated molecular mass is $10,808 \mathrm{Da}$; the observed molecular mass is 10,807 Da. 
(A)

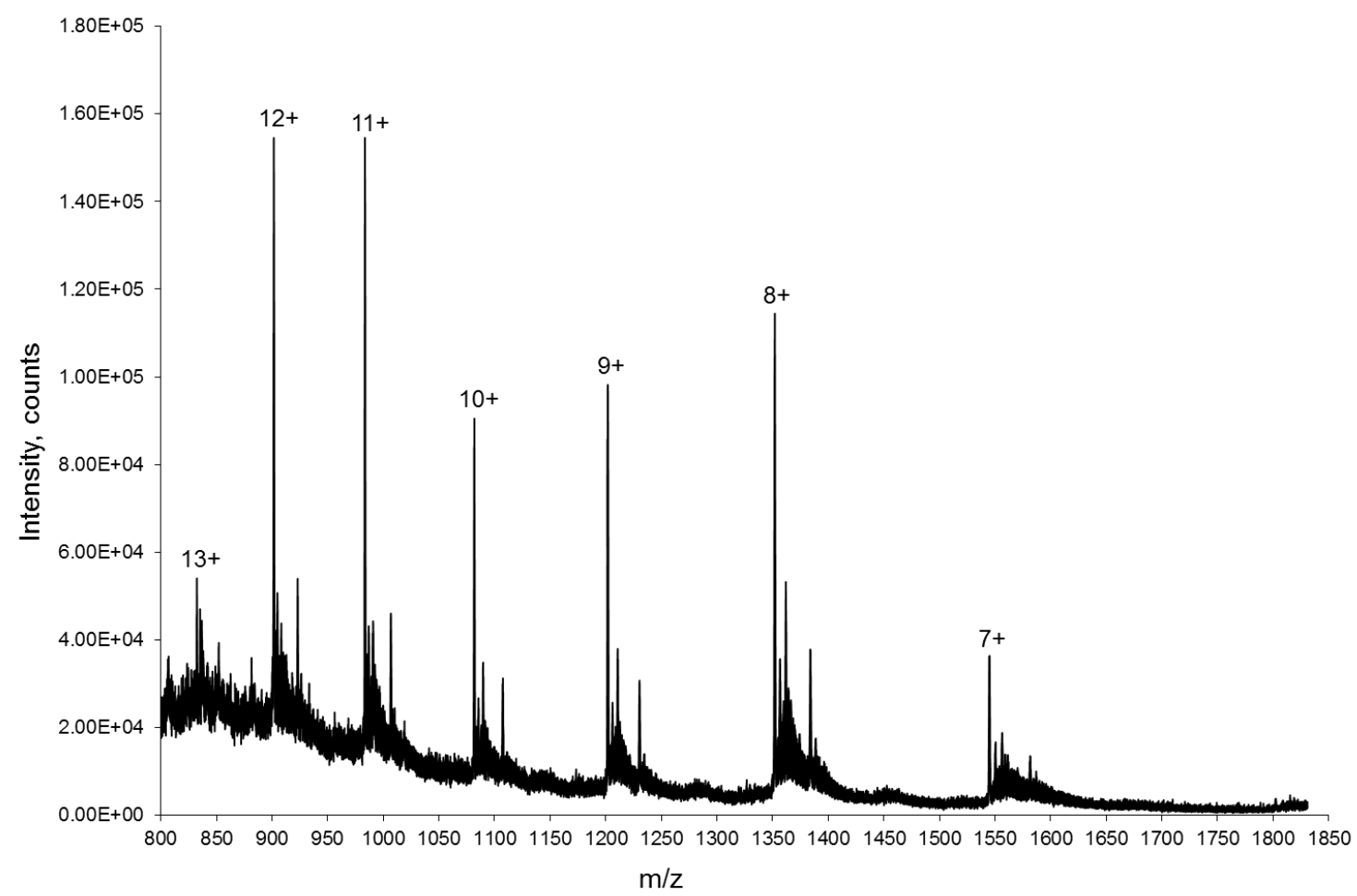

(B)

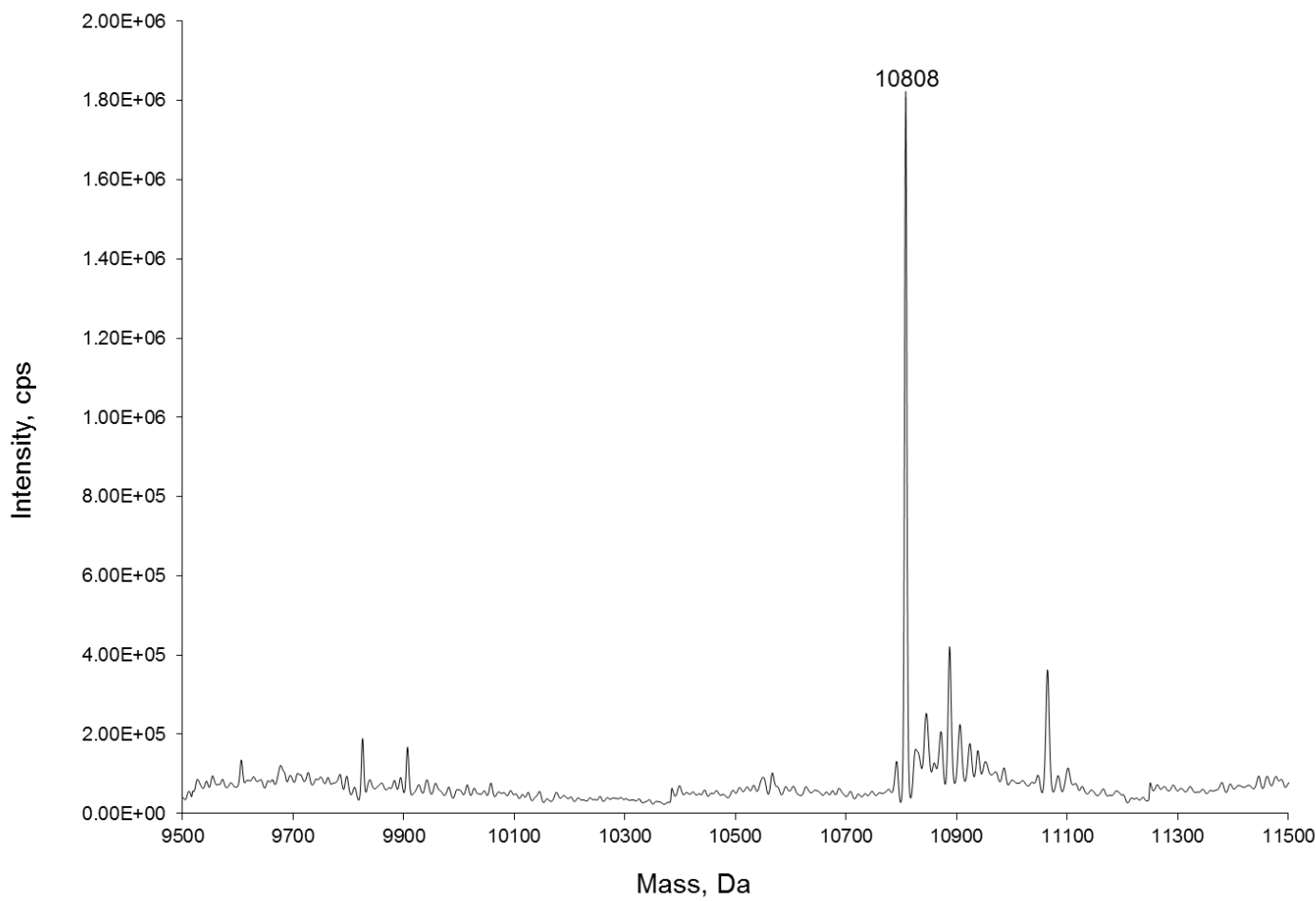

Figure S2. Molecular mass characterization of SUMO2-K7SeCbzK.

(A) ESI-MS spectrum of SUMO2-K7SeCbzK; (B) The deconvoluted ESI-MS spectrum of SUMO2K7SeCbzK. The calculated molecular mass is $10,808 \mathrm{Da}$; the observed molecular mass is 10,808 Da. 
(A)

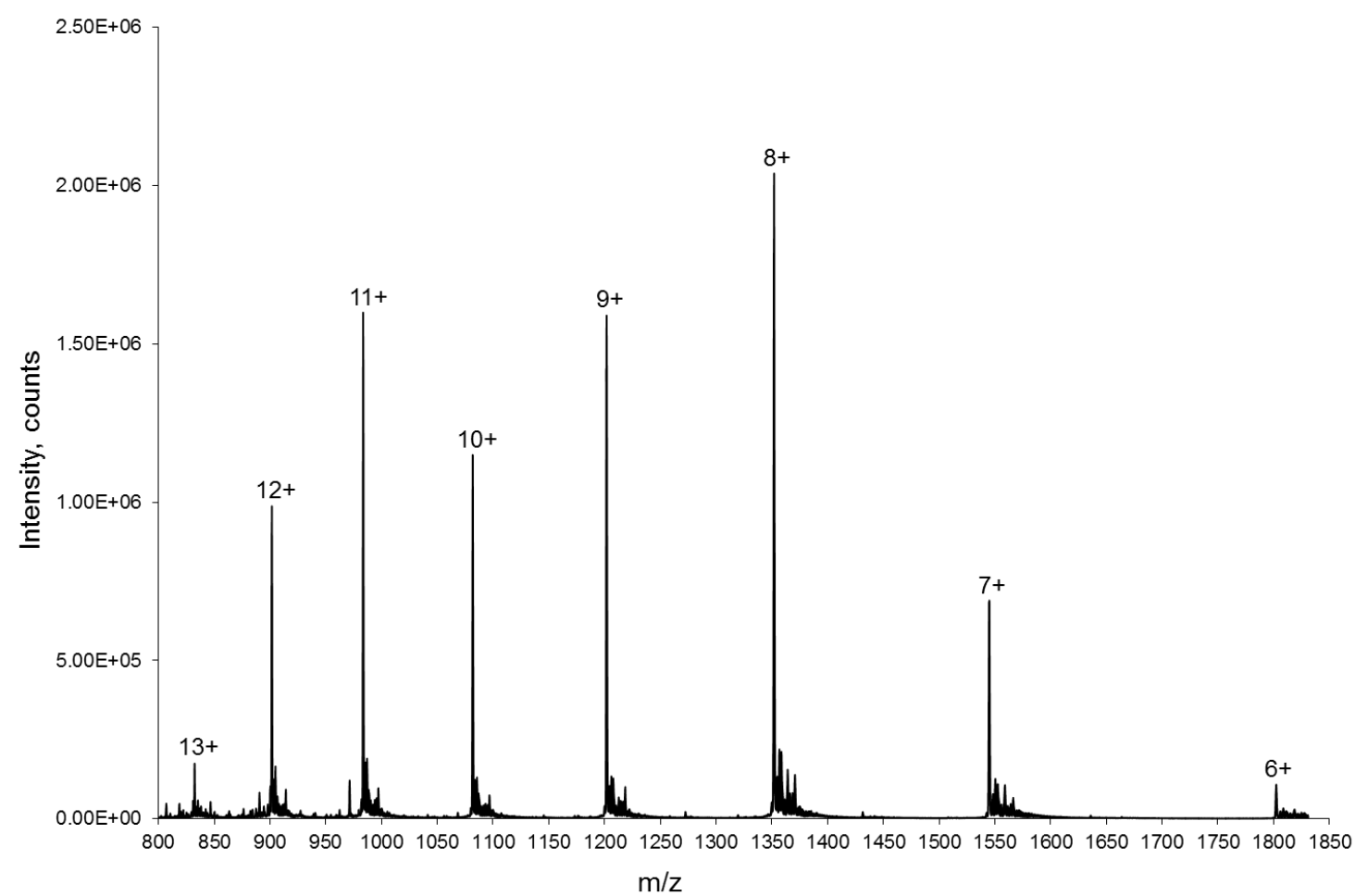

(B)

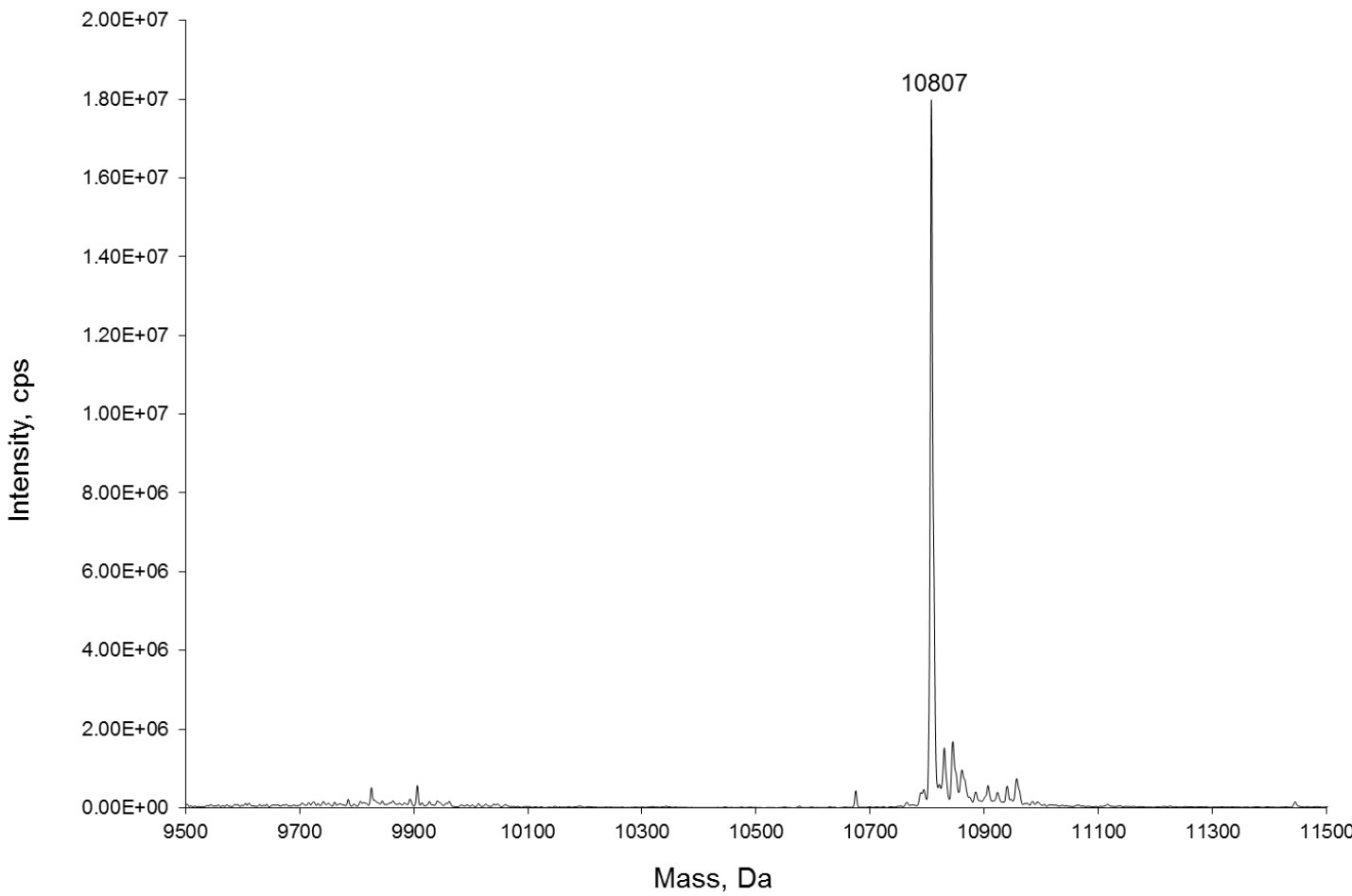

Figure S3. Molecular mass characterization of SUMO2-K11SeCbzK

(A) ESI-MS spectrum of SUMO2-K11SeCbzK; (B) The deconvoluted ESI-MS spectrum of SUMO2K11SeCbzK. The calculated molecular mass is $10,808 \mathrm{Da}$; the observed molecular mass is 10,807 Da. 
(A)

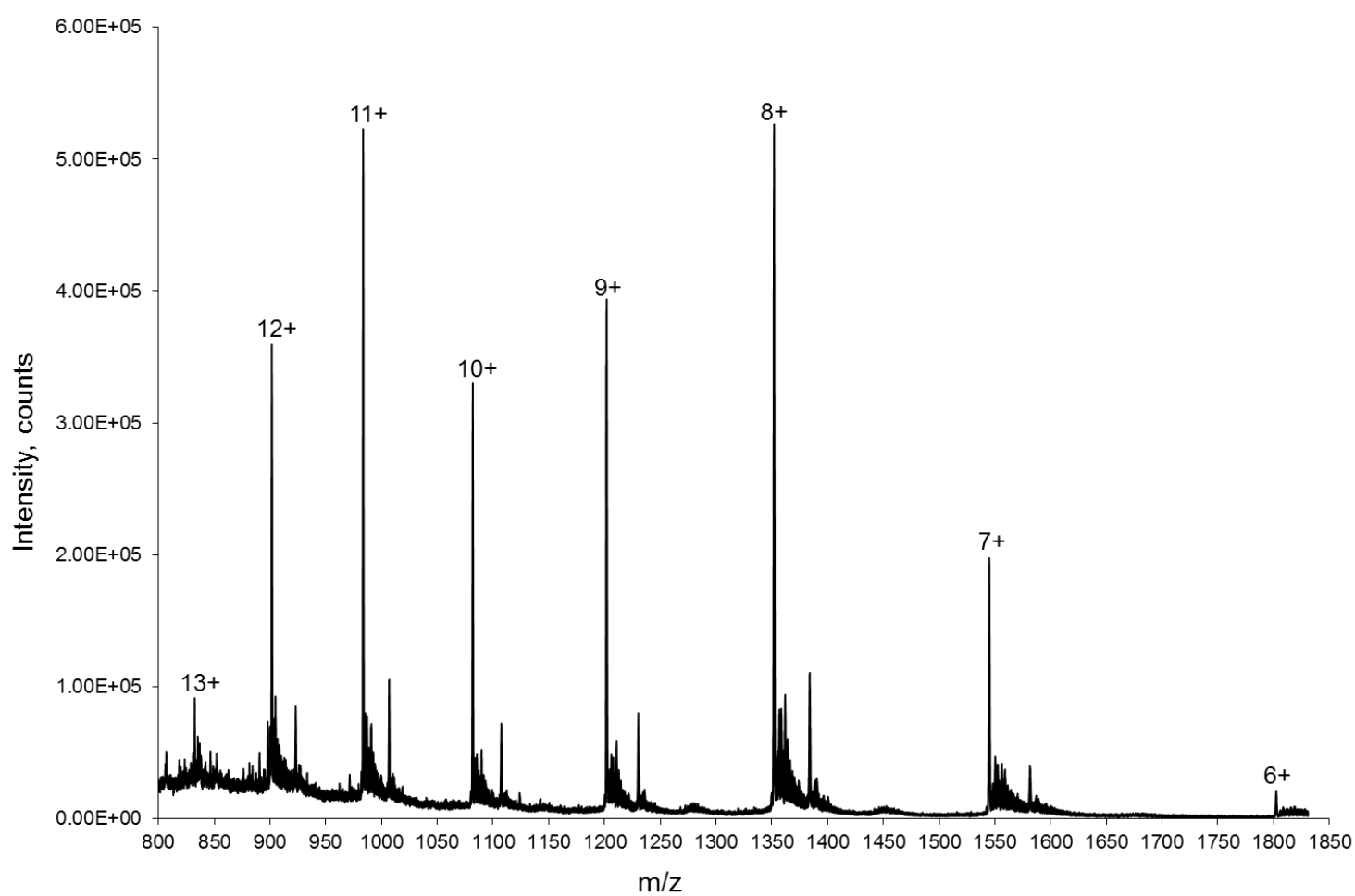

(B)

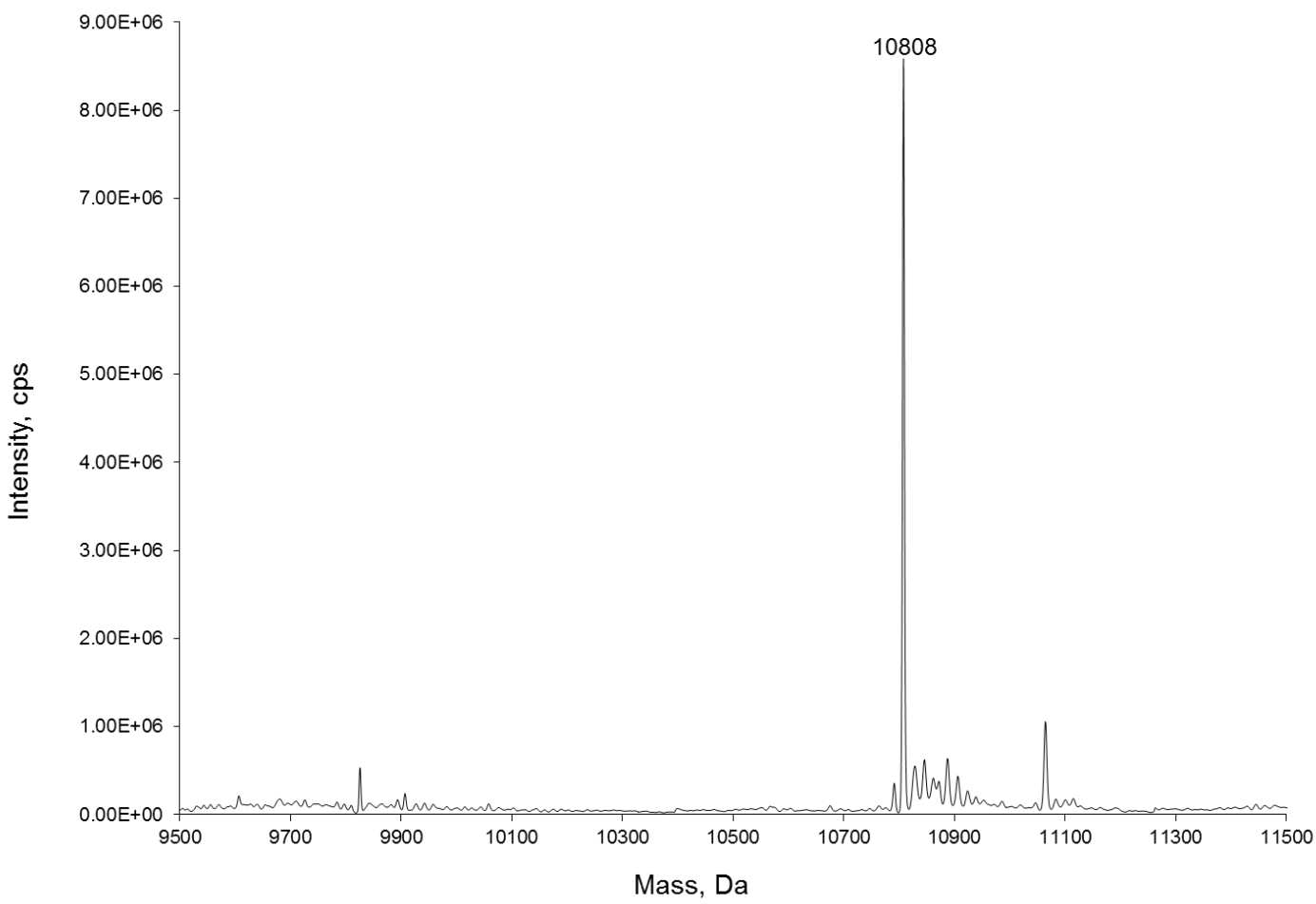

Figure S4. Molecular mass characterization of SUMO2-K21SeCbzK.

(A) ESI-MS spectrum of SUMO2-K21SeCbzK; (B) The deconvoluted ESI-MS spectrum of SUMO2K21SeCbzK. The calculated molecular mass is $10,808 \mathrm{Da}$; the observed molecular mass is 10,808 Da. 
(A)

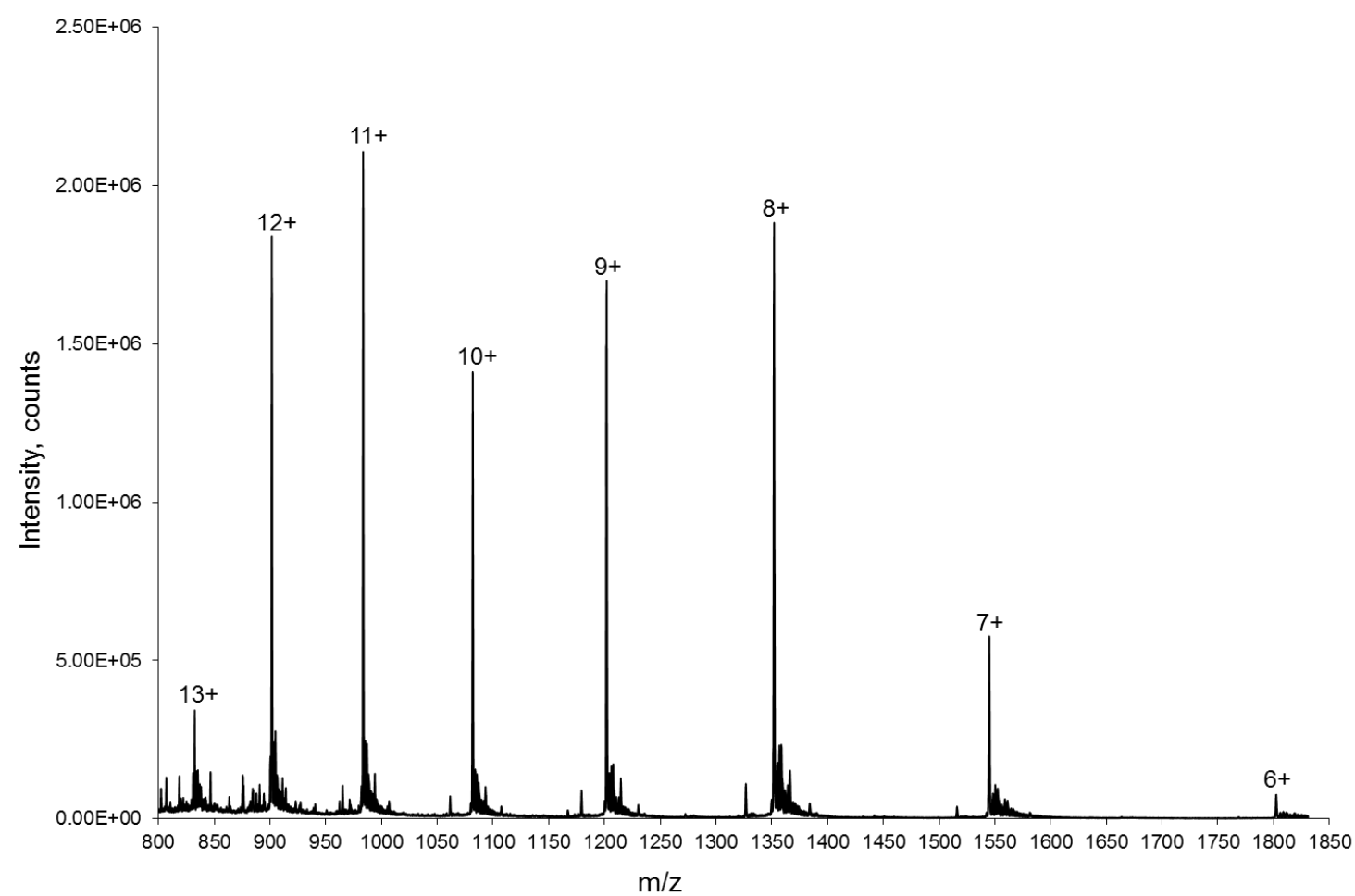

(B)

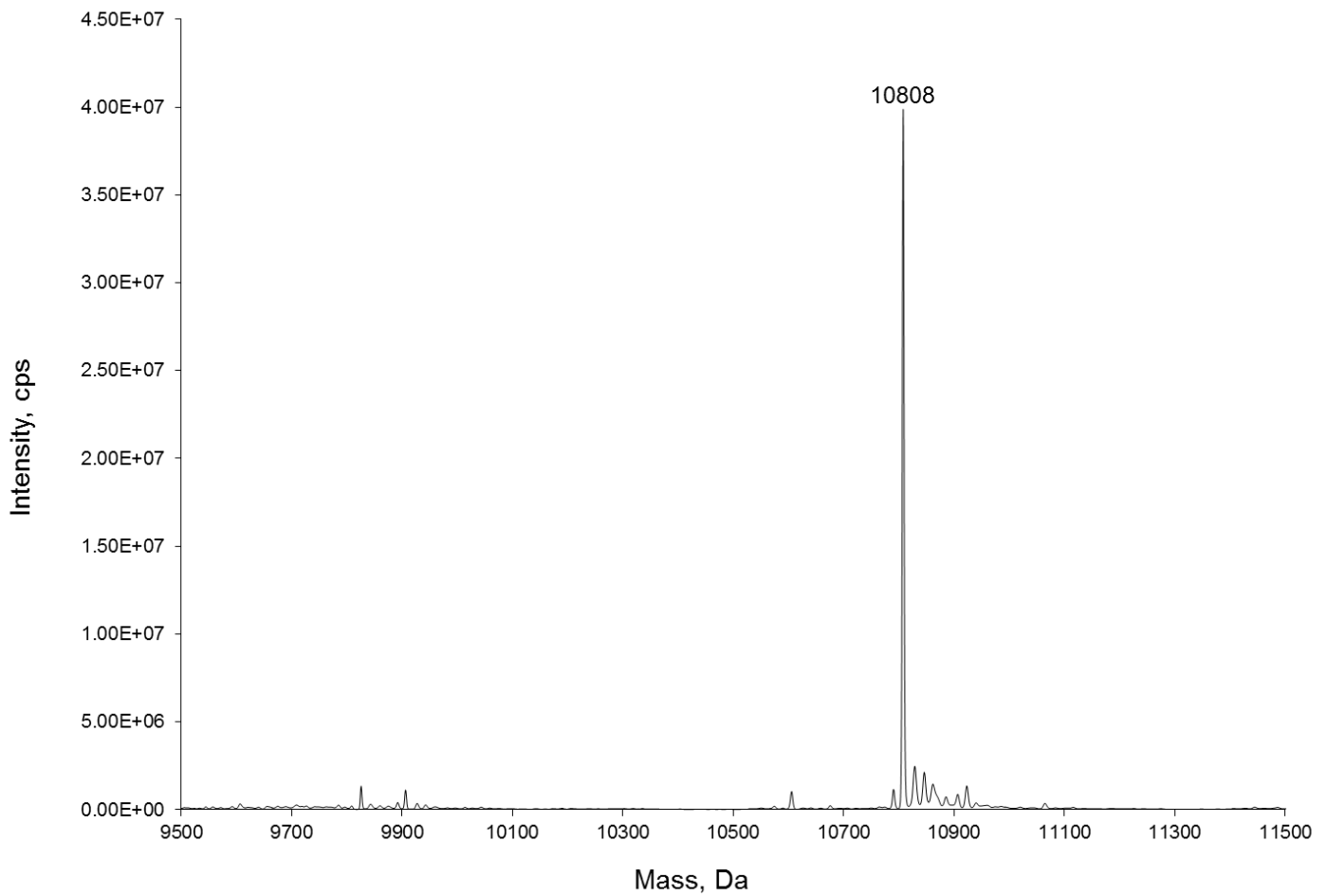

Figure S5. Molecular mass characterization of SUMO2-K33SeCbzK.

(A) ESI-MS spectrum of SUMO2-K33SeCbzK; (B) The deconvoluted ESI-MS spectrum of SUMO2K33SeCbzK. The calculated molecular mass is $10,808 \mathrm{Da}$; the observed molecular mass is 10,808 Da. 
(A)

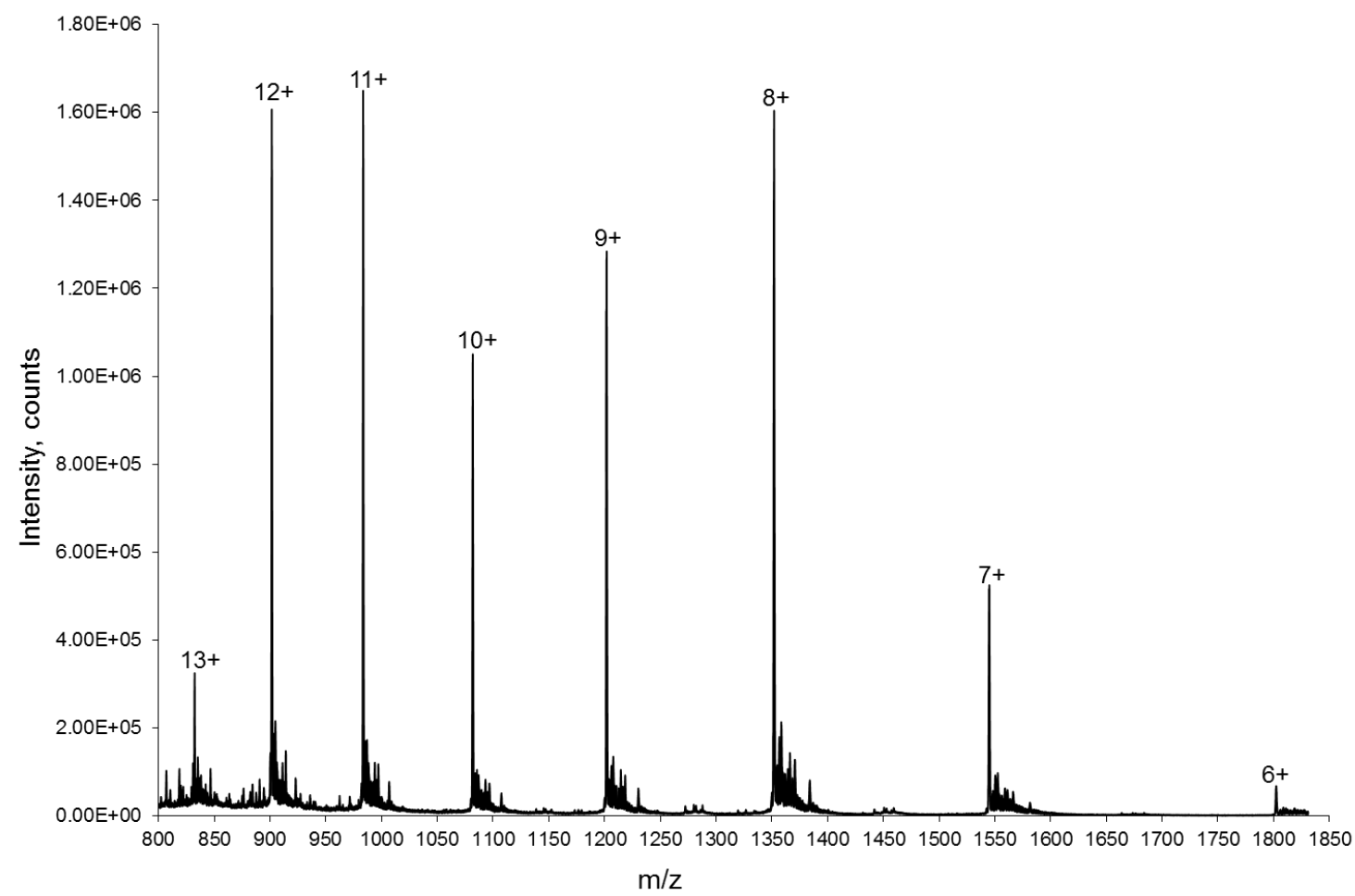

(B)

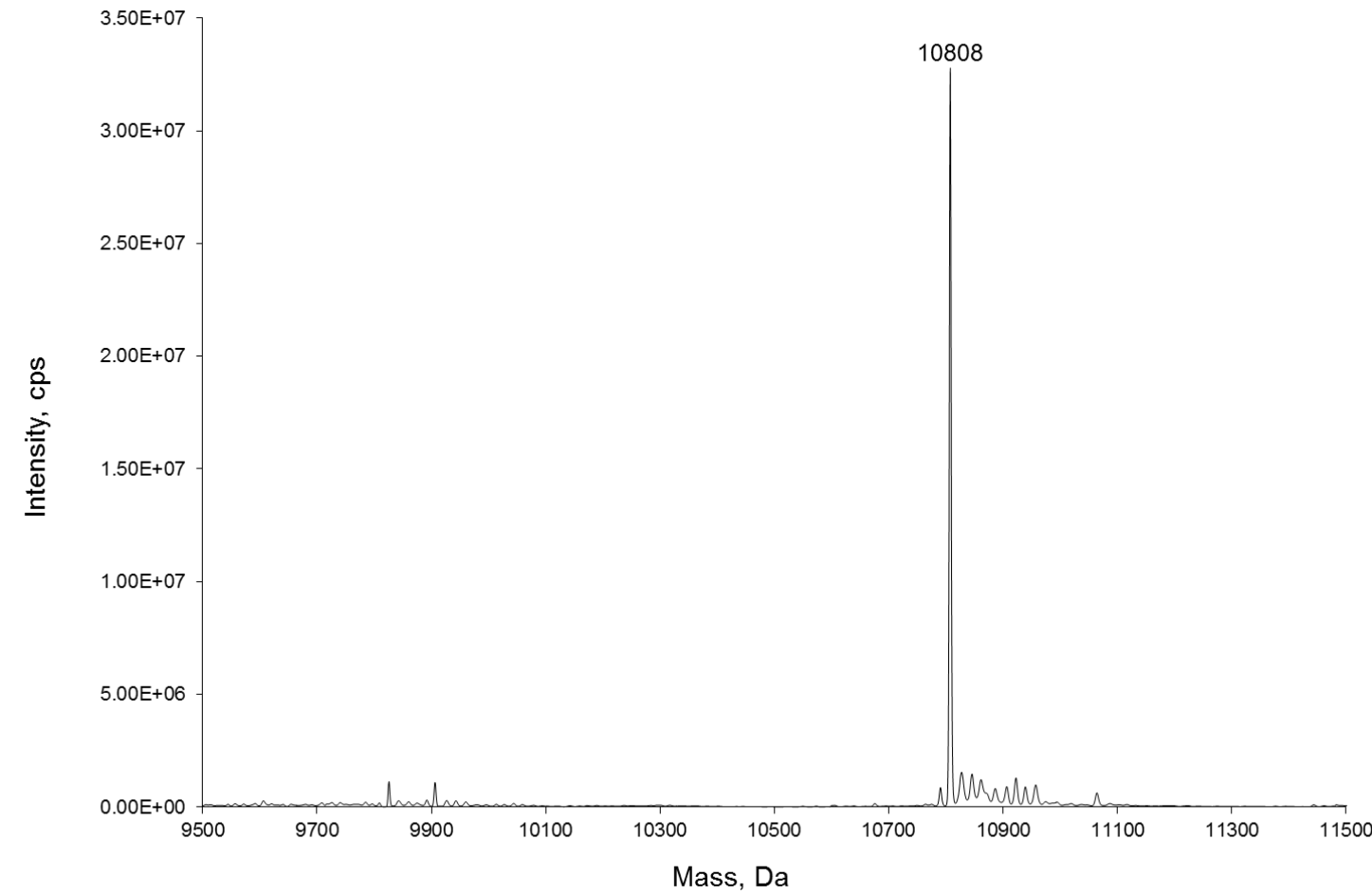

Figure S6. Molecular mass characterization of SUMO2-K35SeCbzK.

(A) ESI-MS spectrum of SUMO2-K35SeCbzK; (B) The deconvoluted ESI-MS spectrum of SUMO2K35SeCbzK. The calculated molecular mass is $10,808 \mathrm{Da}$; the observed molecular mass is 10,808 Da. 
(A)

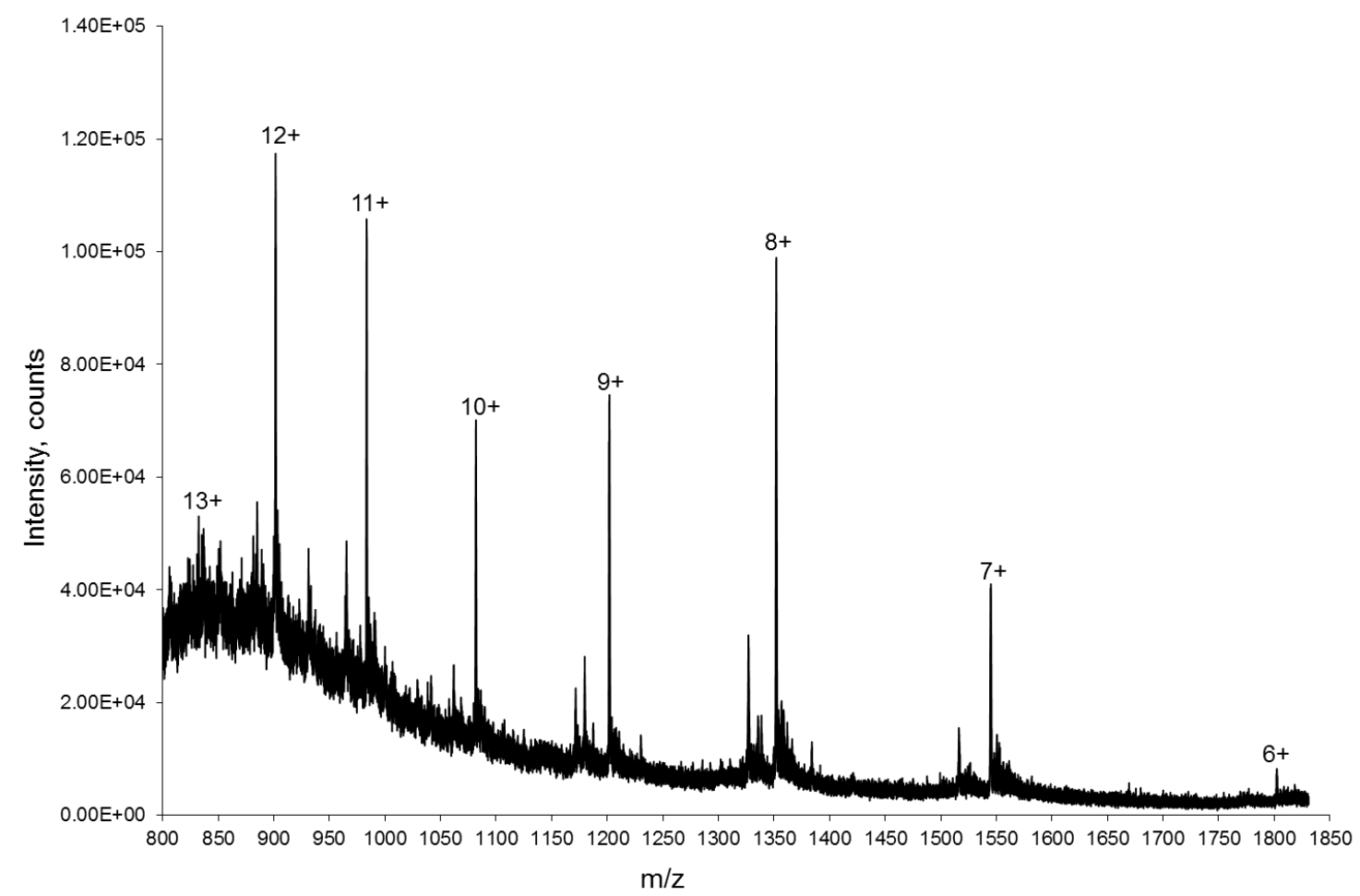

(B)

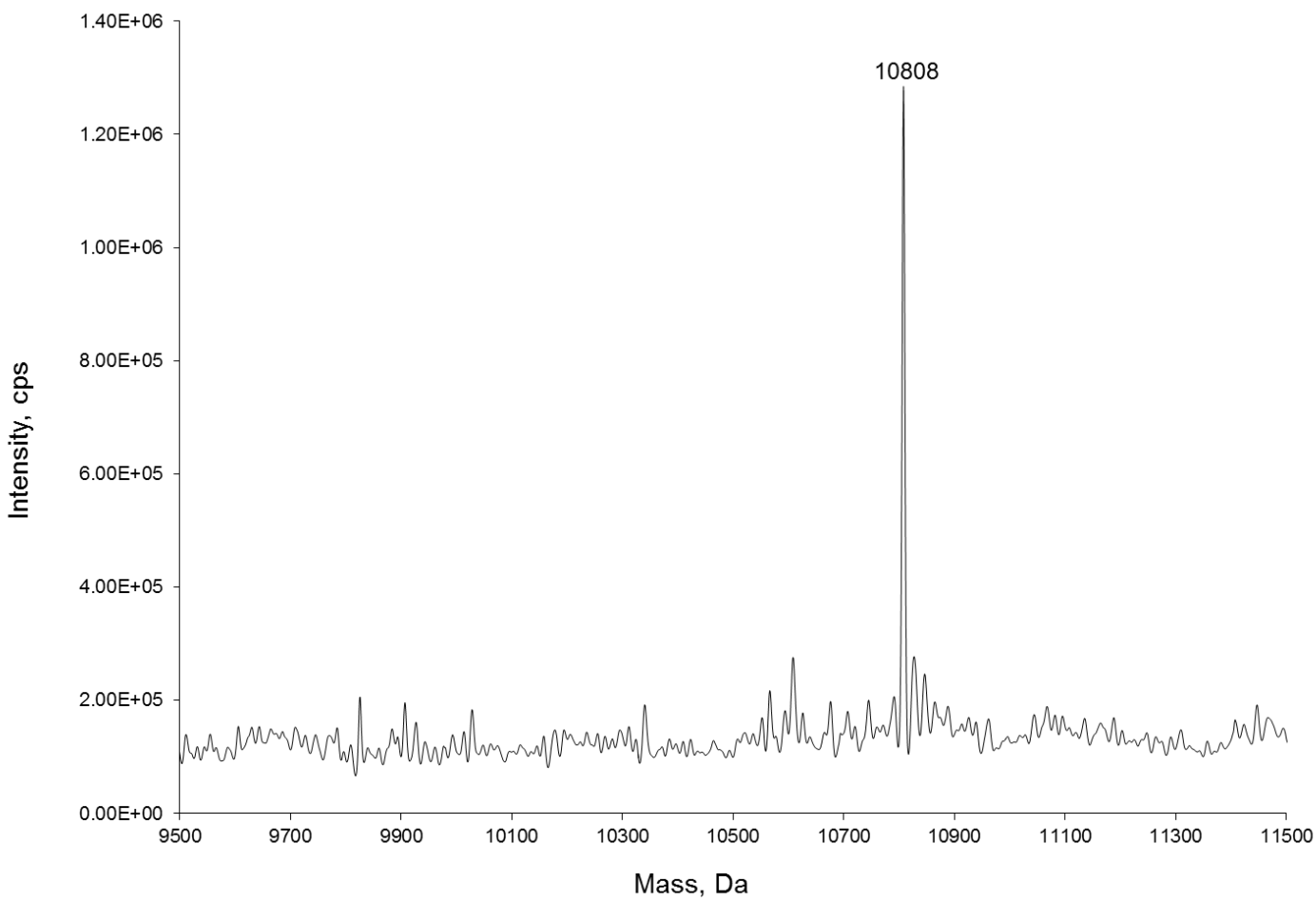

Figure S7. Molecular mass characterization of SUMO2-K42SeCbzK.

(A) ESI-MS spectrum of SUMO2-K42SeCbzK; (B) The deconvoluted ESI-MS spectrum of SUMO2K42SeCbzK. The calculated molecular mass is $10,808 \mathrm{Da}$; the observed molecular mass is 10,808 Da. 
(A)

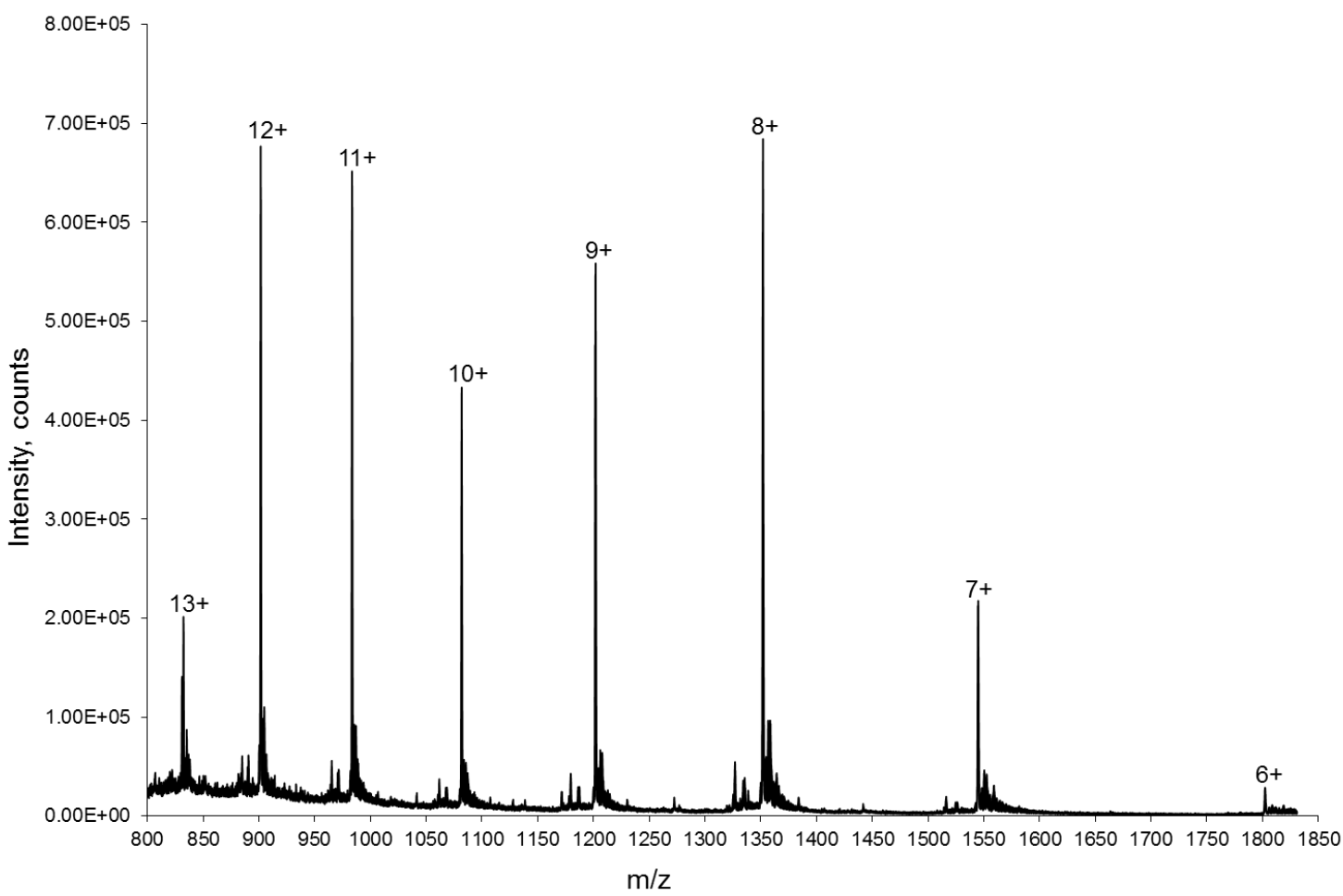

(B)

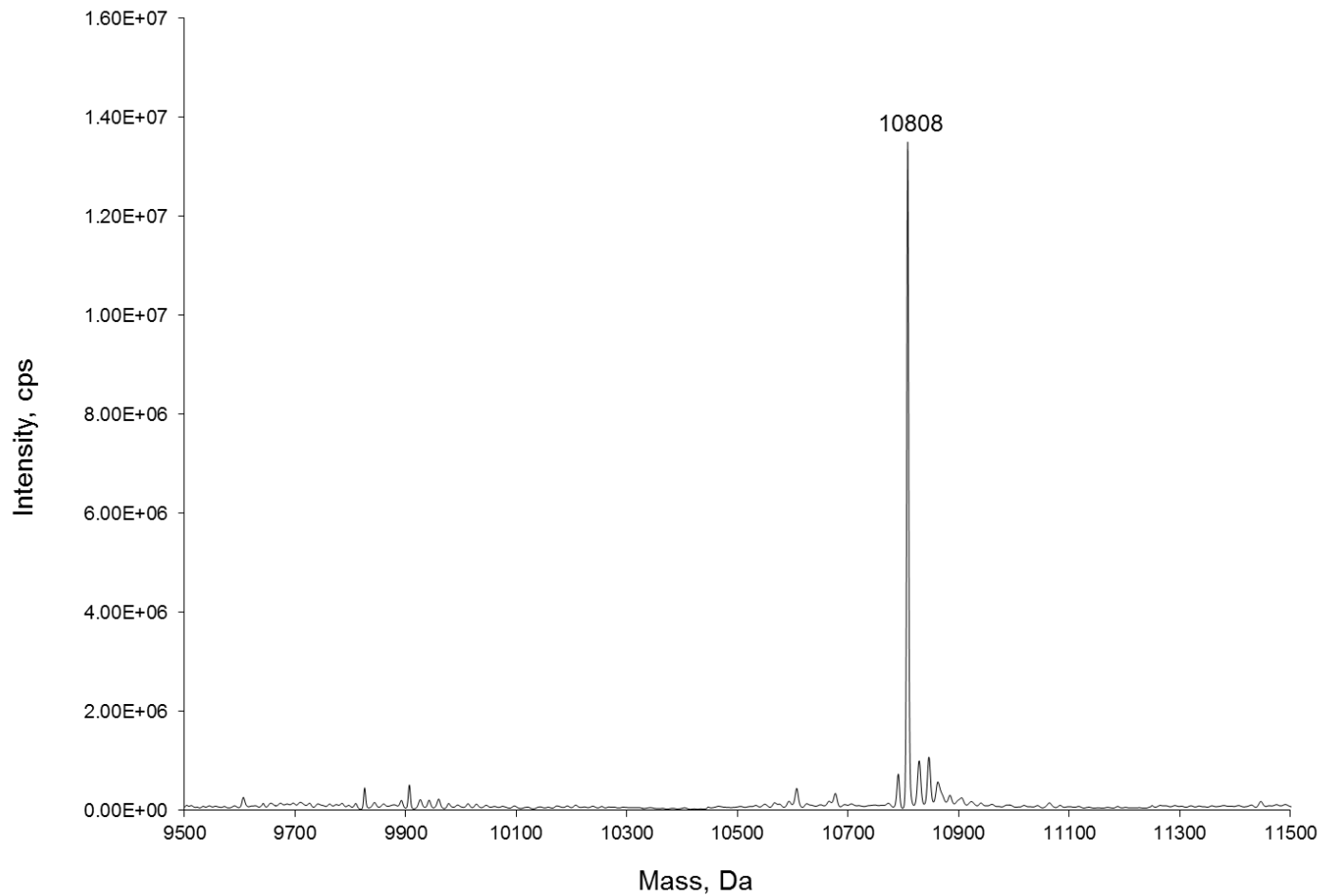

Figure S8. Molecular mass characterization of SUMO2-K45SeCbzK.

(A) ESI-MS spectrum of SUMO2-K45SeCbzK; (B) The deconvoluted ESI-MS spectrum of SUMO2K45SeCbzK. The calculated molecular mass is $10,808 \mathrm{Da}$; the observed molecular mass is 10,808 Da. 
(A)

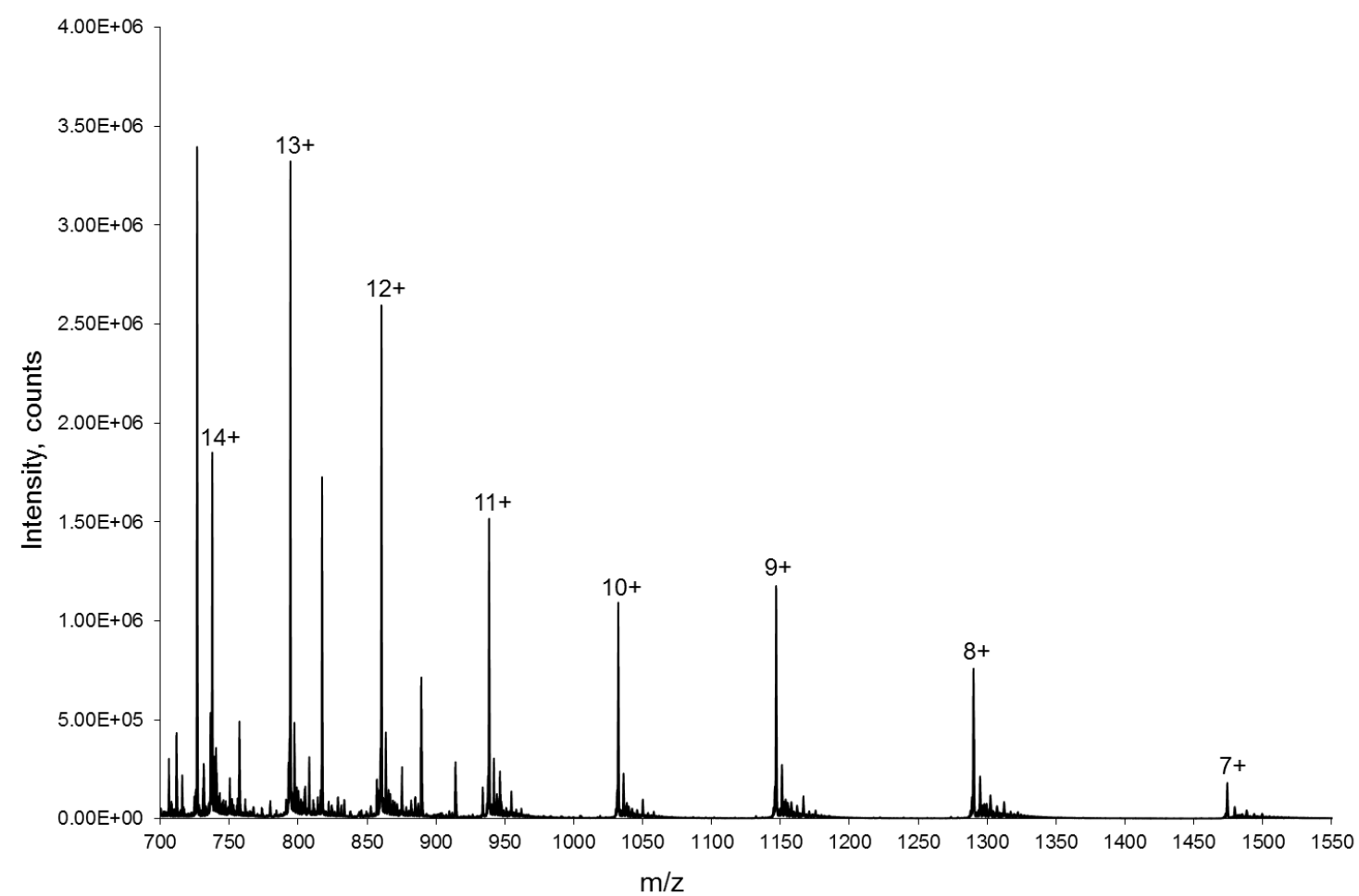

(B)

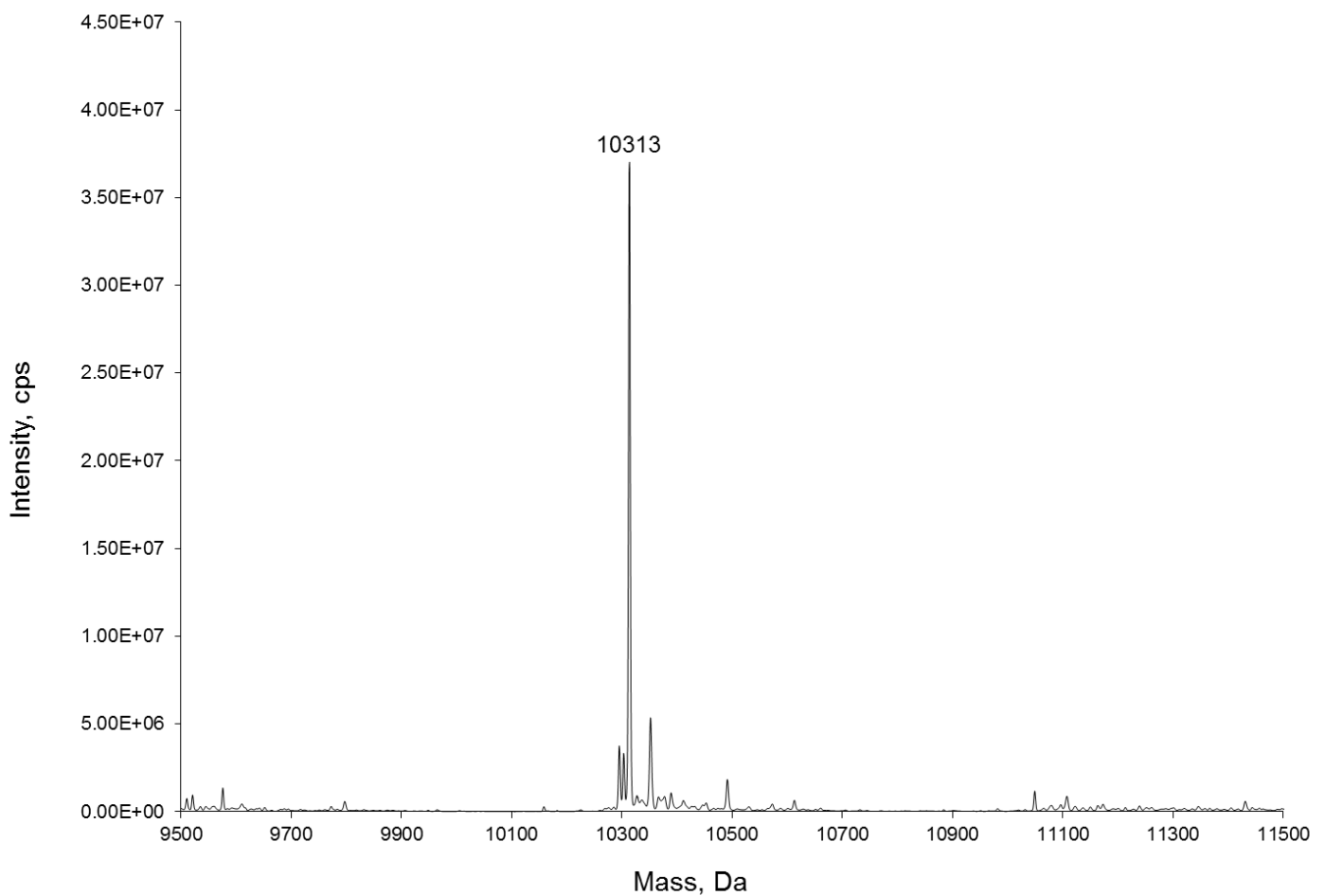

Figure S9. Molecular mass characterization of Ub.

(A) ESI-MS spectrum of Ub; (B) The deconvoluted ESI-MS spectrum of Ub. The calculated molecular mass is $10,314 \mathrm{Da}$; the observed molecular mass is $10,313 \mathrm{Da}$. 
(A)

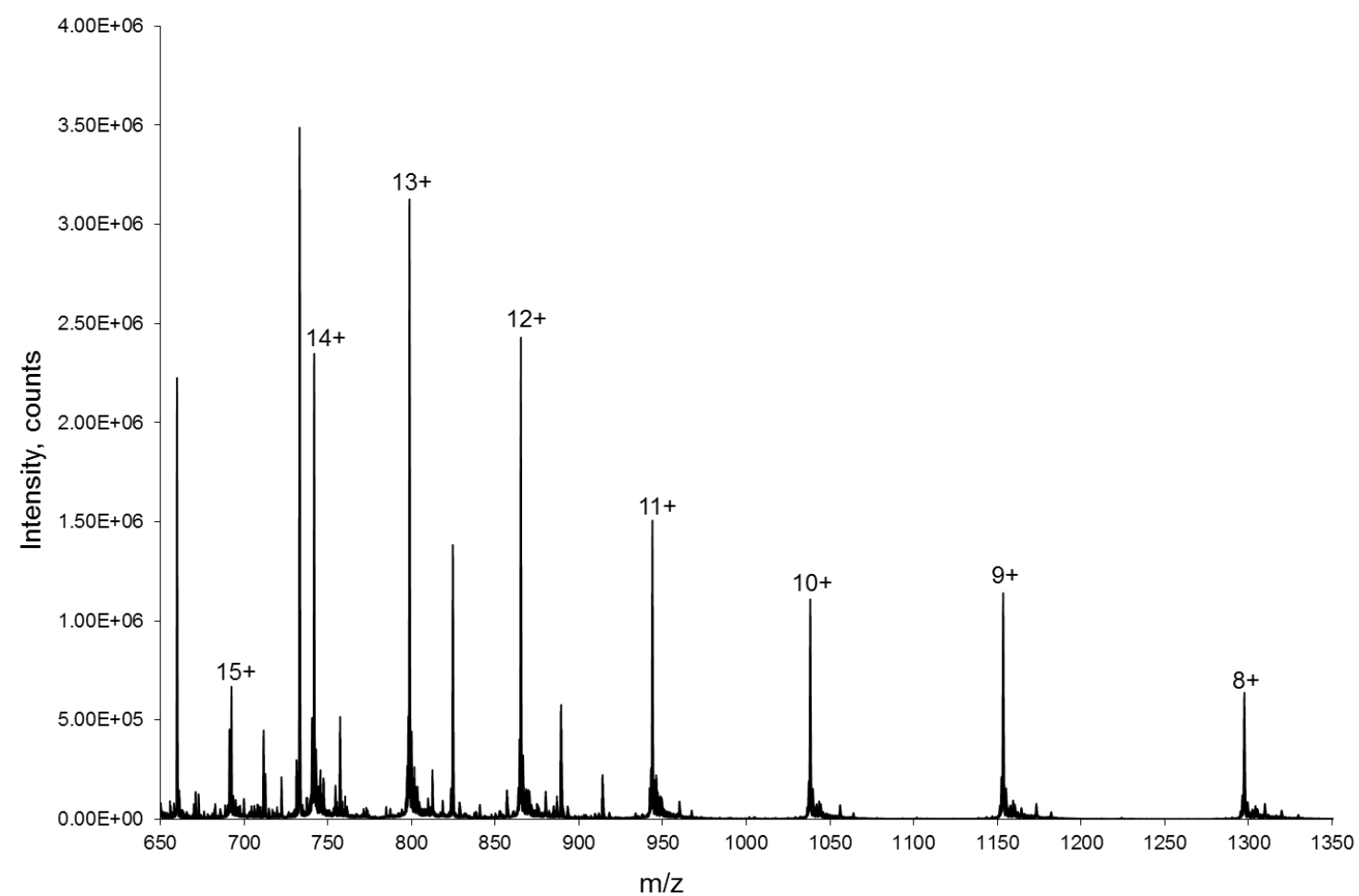

(B)

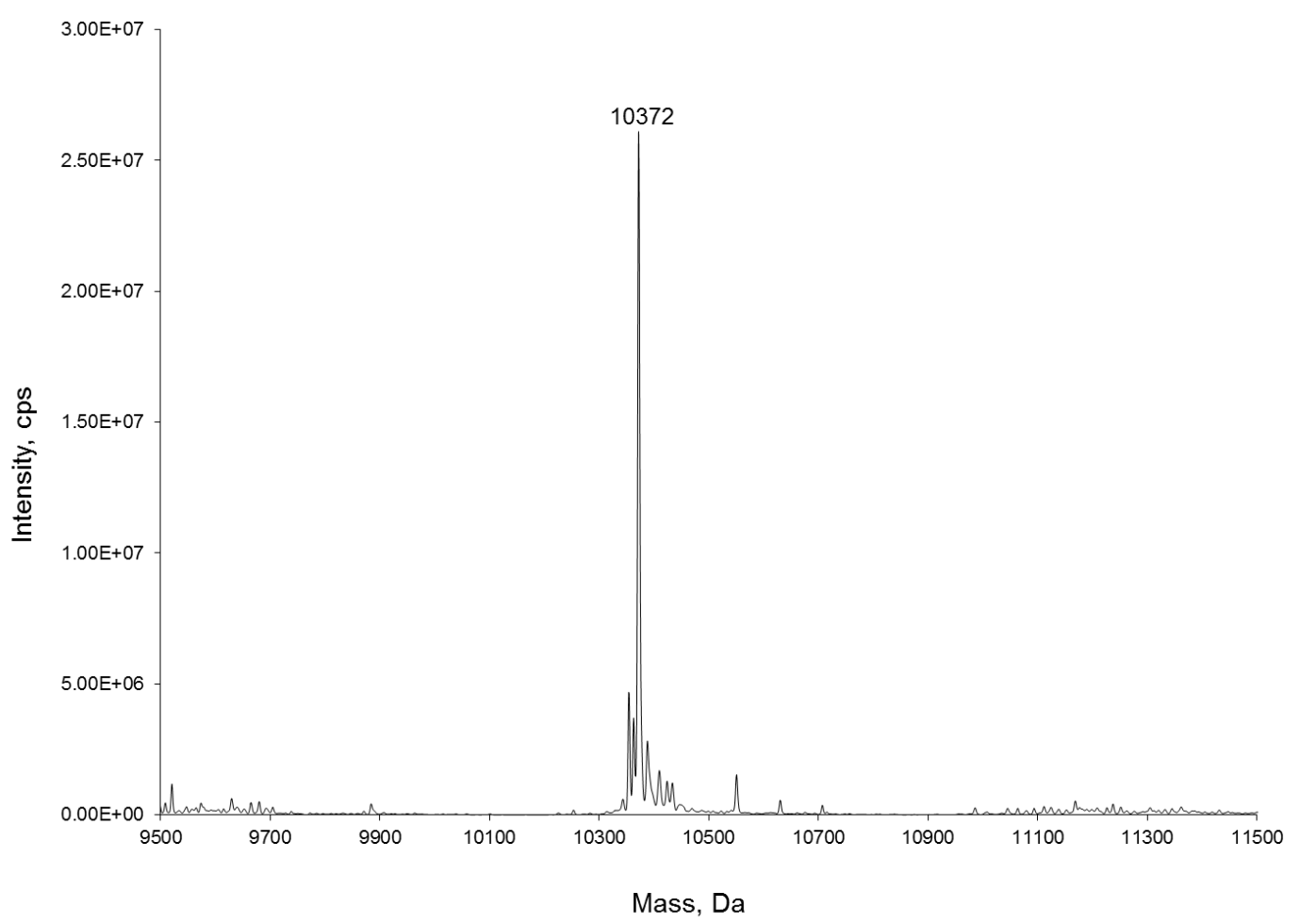

Figure S10. Molecular mass characterization of Ub-SH.

$\mathrm{Ub}-\mathrm{SH}$ was prepared by $\mathrm{Ub}$ E1 enzyme in the presence of cysteamine. (A) ESI-MS spectrum of Ub$\mathrm{SH}$; (B) The deconvoluted ESI-MS spectrum of $\mathrm{Ub}-\mathrm{SH}$. The calculated molecular mass is $10,373 \mathrm{Da}$; the observed molecular mass is $10,372 \mathrm{Da}$. 
(A)

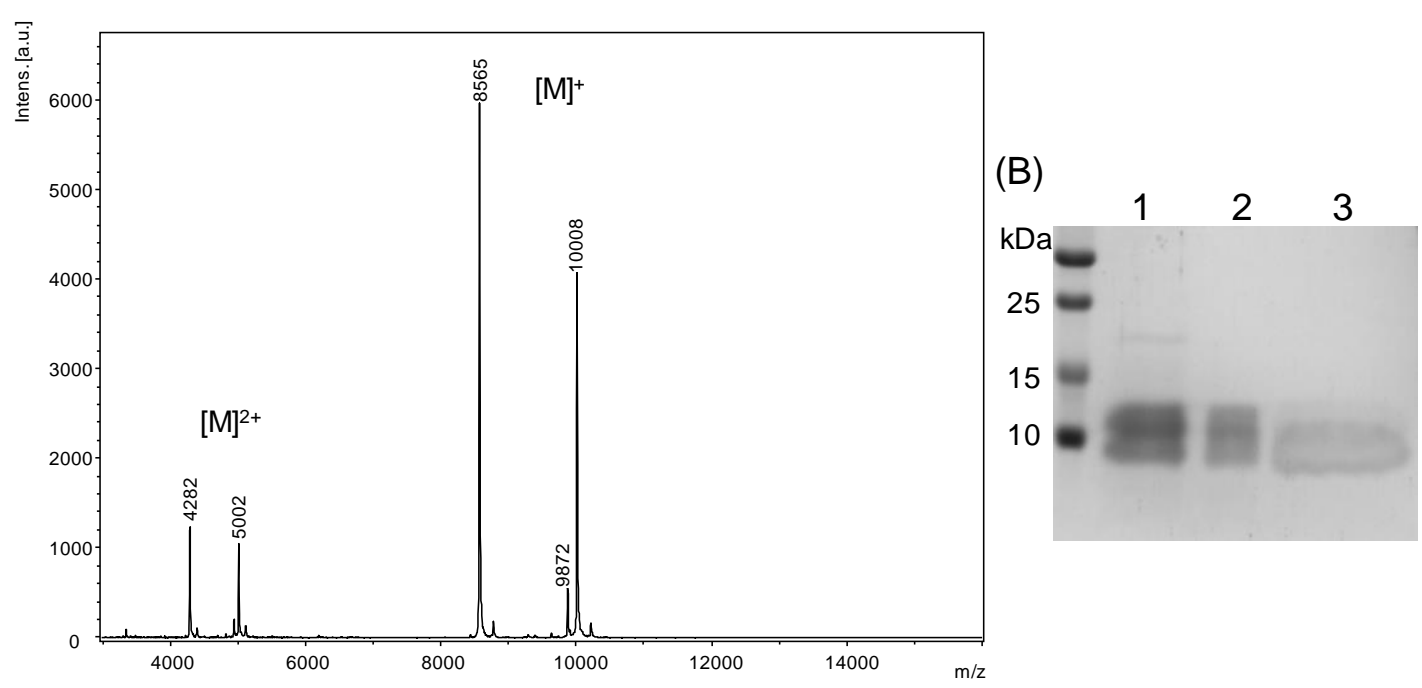

(C)

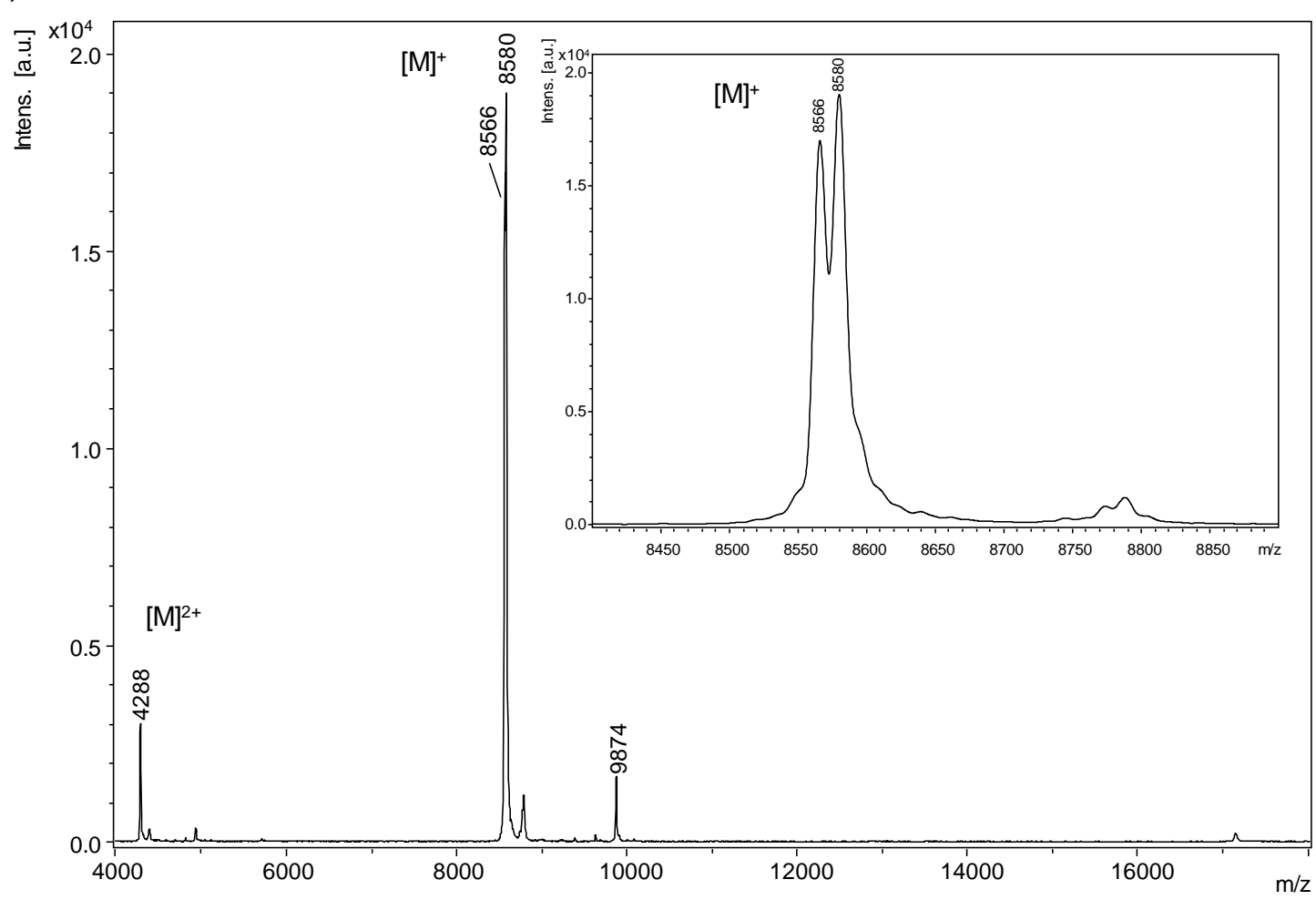

Figure S11. Molecular mass characterization and SDS-PAGE analysis of $\mathrm{Ub}-77 \mathrm{CbzKOH}$ and Ub-NHNH

(A)The MALDI-TOF-MS spectrum of Ub-77CbzKOH. The calculated molecular mass is $10,007 \mathrm{Da}$ and the observed molecular masses [M] ${ }^{+}$are $10,008 \mathrm{Da}, 8,565 \mathrm{Da}$ (truncation at Ub-76 position), and $9,872 \mathrm{Da}$ (K or $\mathrm{Q}$ incorporation). The observed masses [M] ${ }^{2+}$ are 5,002 and 4,282 $\mathrm{Da}$; (B) The SDSPAGE analysis of $\mathrm{Ub}-77 \mathrm{CbzKOH}$ after hydrazinolysis. Lane 1 and 2: purified $\mathrm{Ub}-77 \mathrm{CbzKOH}$ by $\mathrm{Ni}^{2+}$ affinity chromatography; lane 3: $\mathrm{Ub}-77 \mathrm{CbzKOH}$ after hydrazinolysis in $0.1 \mathrm{M} \mathrm{NaCl}, 0.1 \mathrm{M}$ sodium phosphate buffer at pH 7.0; (C) The MALDI-TOF-MS spectrum of Ub-NHNH2. The calculated molecular mass is $8,579 \mathrm{Da}$ and the observed molecular masses [M] ${ }^{+}$are $8,580 \mathrm{Da}, 8,566 \mathrm{Da}$ (truncation at $\mathrm{Ub}-76$ position), and $9874 \mathrm{Da}$ (K or $\mathrm{Q}$ incorporation); the observed molecular mass $[\mathrm{M}]^{2+}$ is $4288 \mathrm{Da}$. The zoom-in figure shows two signals; 8,580 and 8,566 Da. 


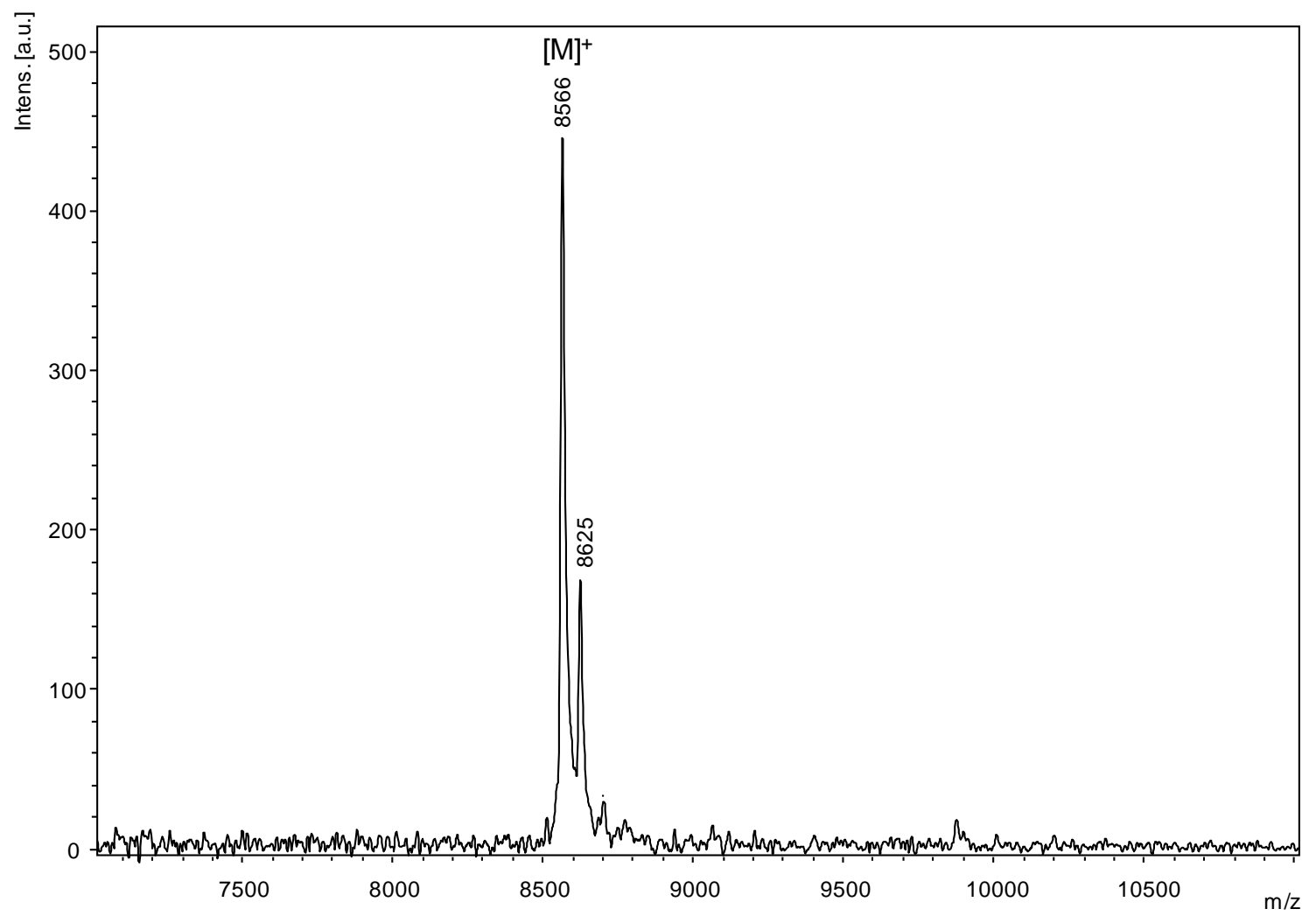

Figure S12. Molecular mass characterization of Ub-SH.

$\mathrm{Ub}-\mathrm{SH}$ was generated from $\mathrm{Ub}-\mathrm{NHNH}_{2}$. The calculated molecular mass is 8,624 $\mathrm{Da}$ and the observed molecular masses are 8,625 $\mathrm{Da}$ and 8,566 $\mathrm{Da}$ (truncation at Ub-76 position). 
(A)

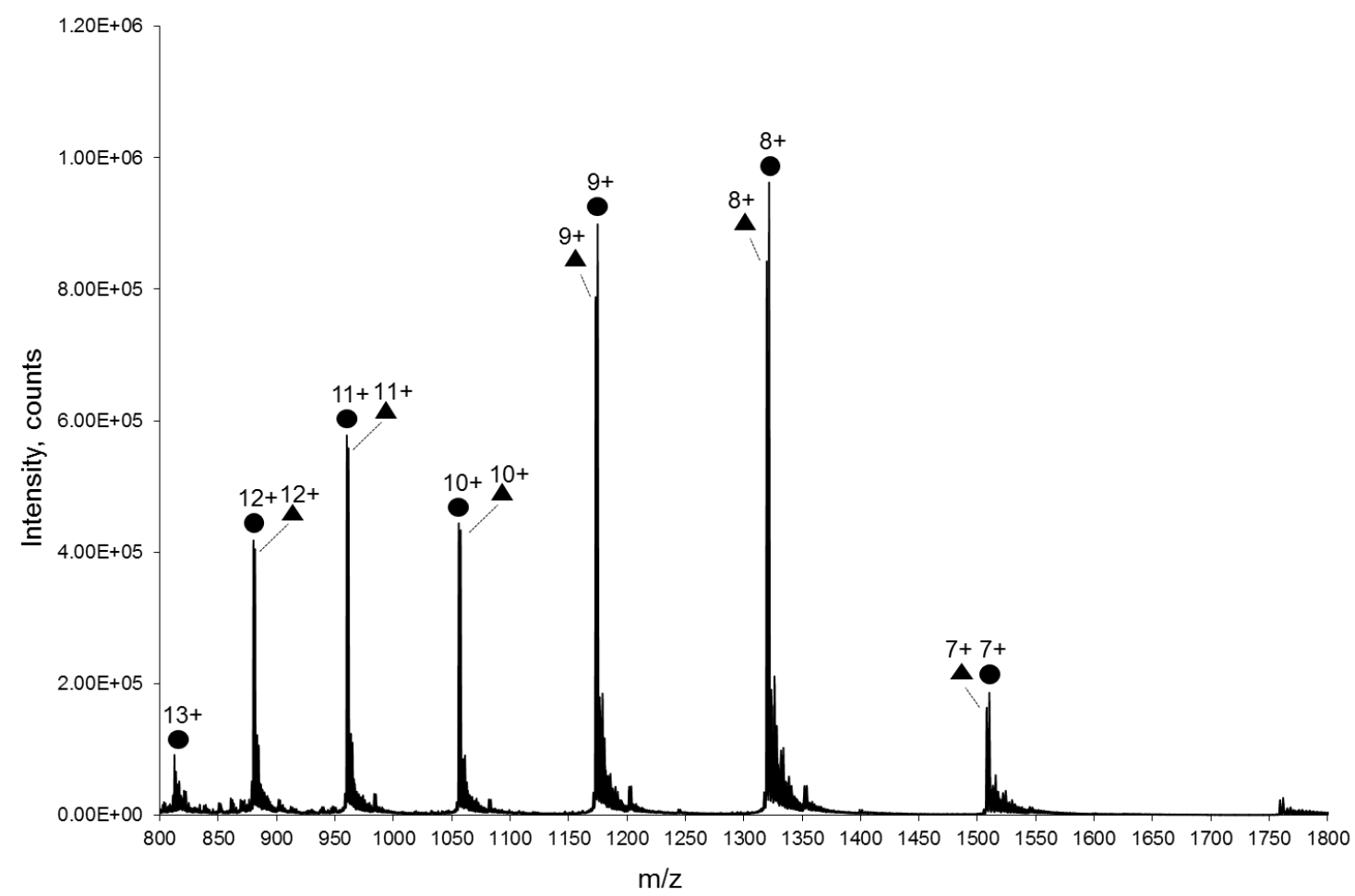

(B)

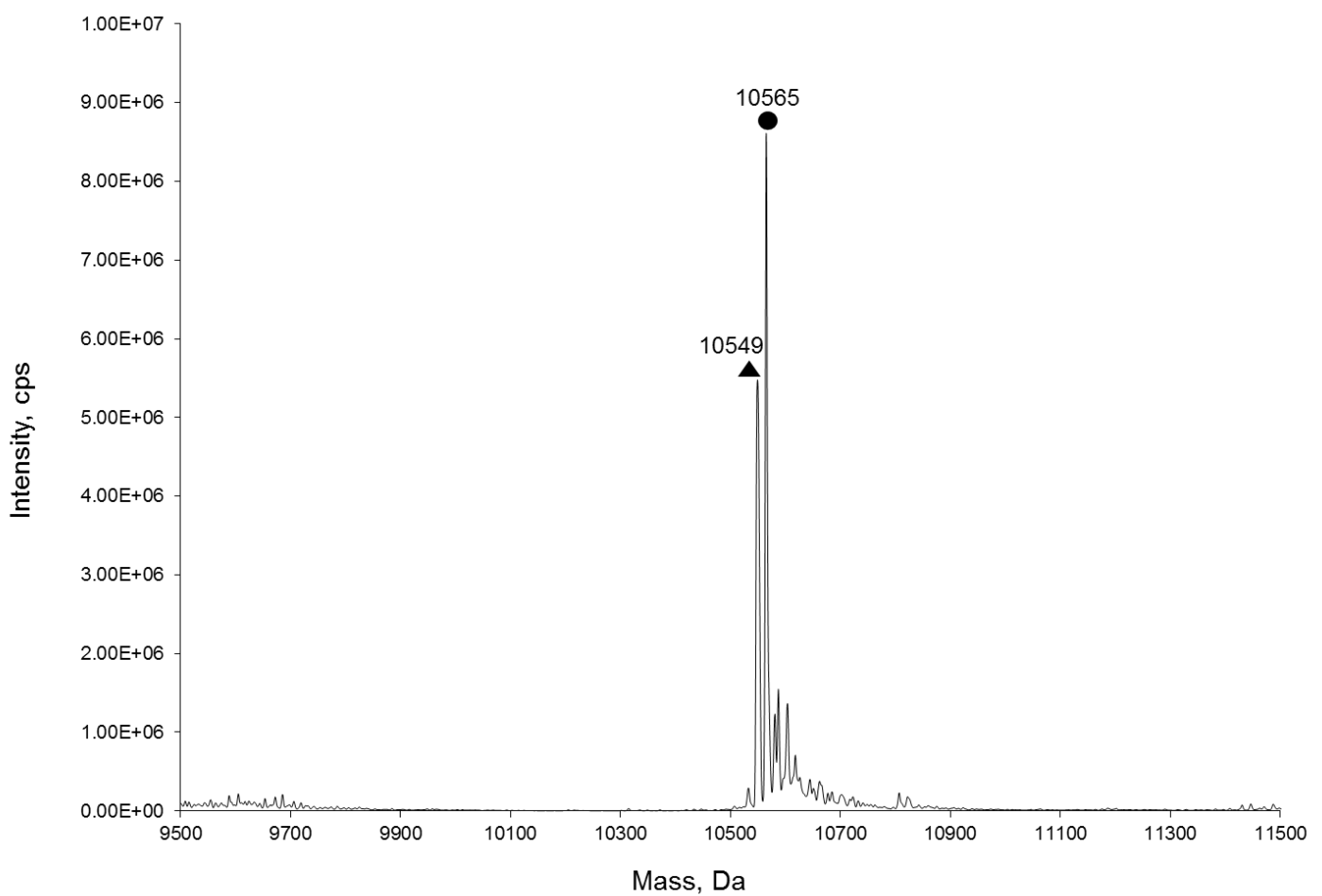

Figure S13. Molecular mass characterization of SUMO2-K11Dha.

The oxidation of SUMO2-K11SeCbzK with hydrogen peroxide to yield SUMO2-K11Dha. (A) ESI-MS spectrum of SUMO2-K11Dha; (B) The deconvoluted ESI-MS spectrum of SUMO2-K11Dha. The calculated molecular weight is $10,550 \mathrm{Da}$; observed molecular masses are 10,549 $\mathrm{Da}$ and 10,565 $\mathrm{Da}$ (with an oxygen adduct). 


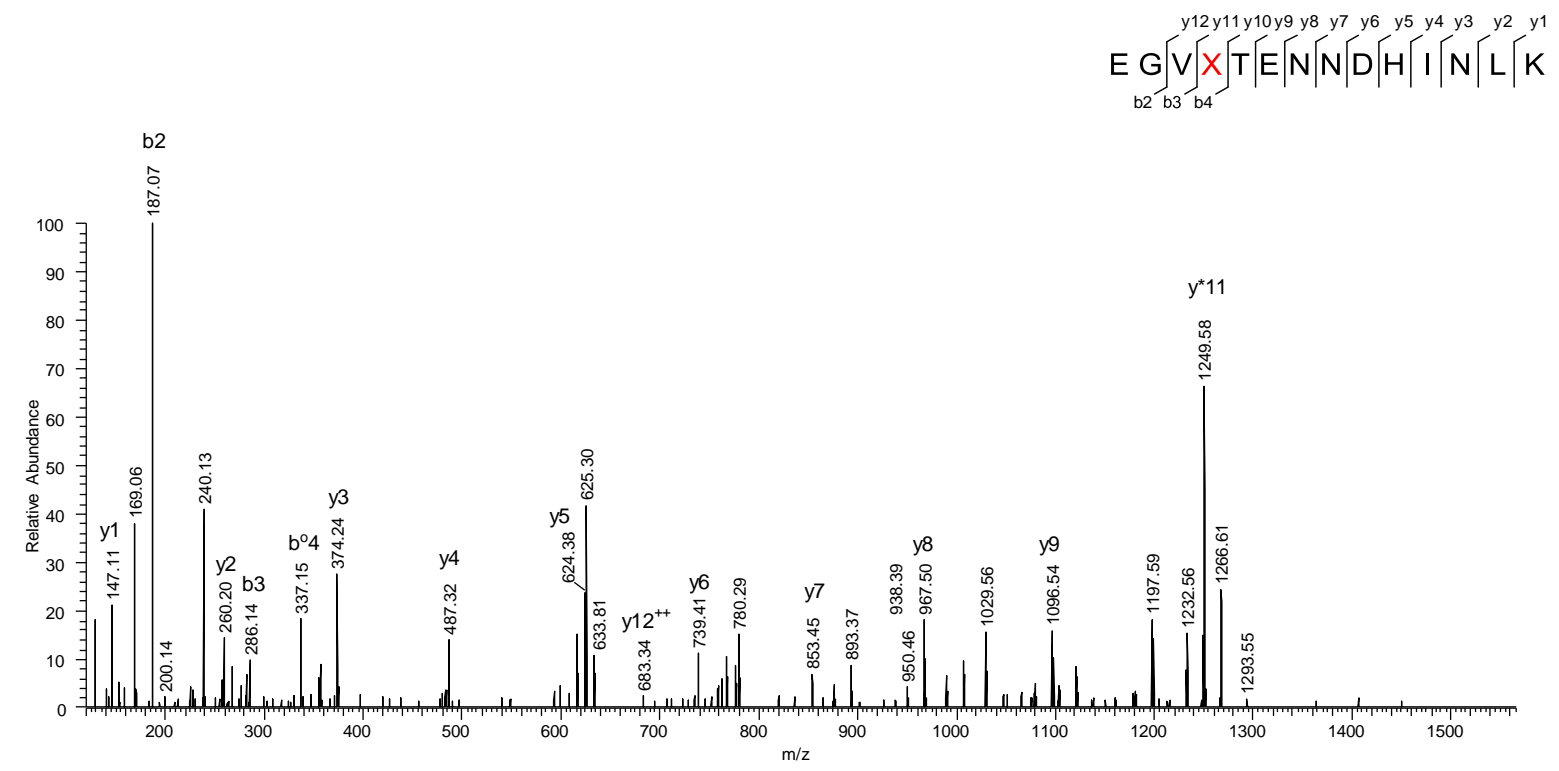

Figure S14. ESI-MS/MS analysis of SUMO2-K11Dha.

The oxidation of SUMO2-K11SeCbzK with hydrogen peroxide to yield SUMO2-K11Dha; $X$ denotes Dha incorporated at position 11 in the fragment from SUMO2-K11Dha. The protein was in-gel digested by trypsin. 


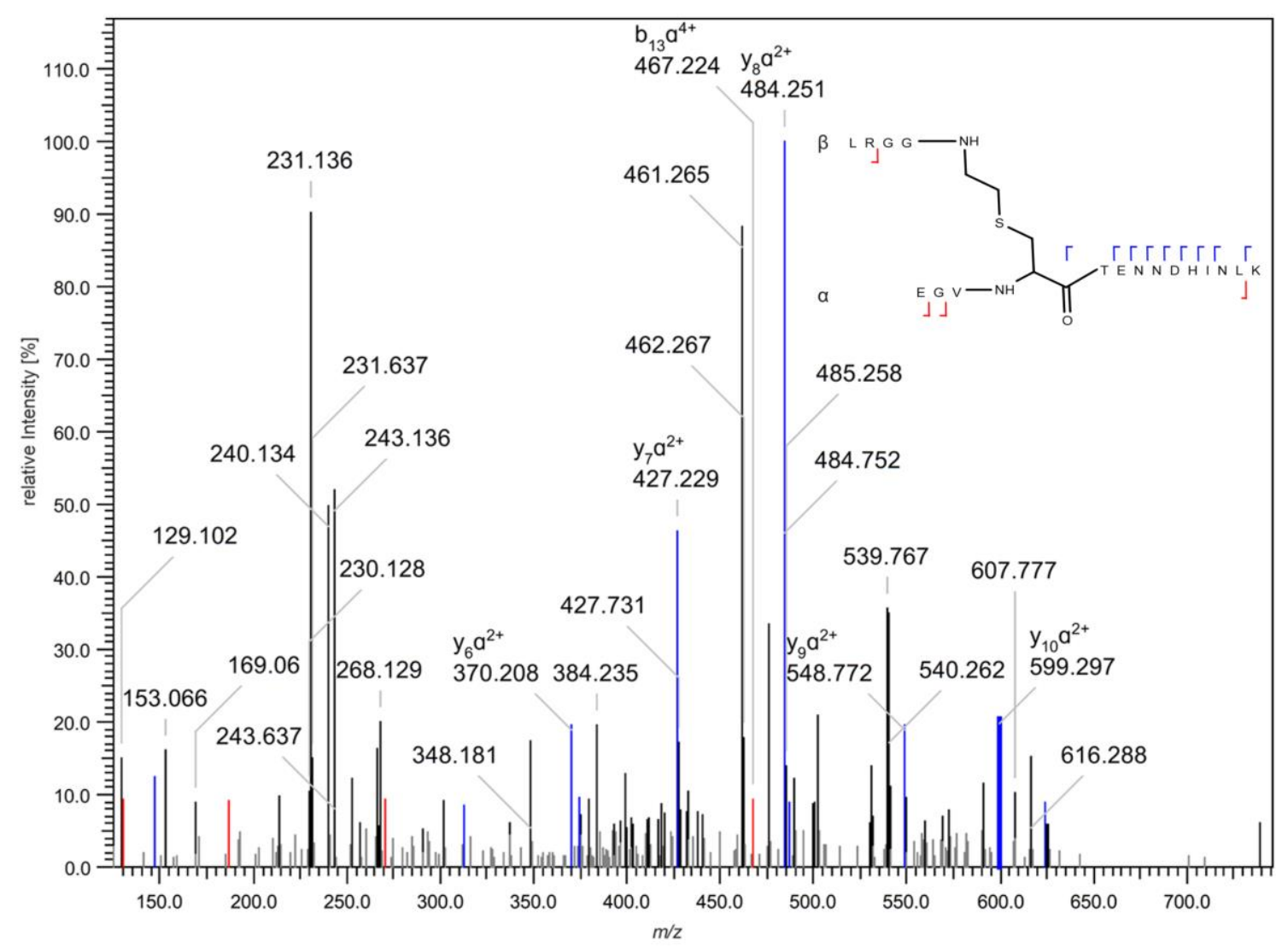

Figure S15. ESI-MS/MS analysis of Ub-K11SUMO2 heterodimer.

The higher-energy collisional dissociation fragment ion mass spectra of a fifthly charged precursor ion at $m / z$ 403.2056, presenting an isopeptide bond mimic cross-link within Ub-SUMO2 between Dha-11 (a-peptide, aa 8 to 21) and Gly-76 ( $\beta$-peptide, aa 73-76). The protein was in-gel digested by Lys-C and trypsin. The cross-linked peptides were analyzed using StavroX. The blue peaks represent y ions and the red ones represent $b$ ions. 
(A)

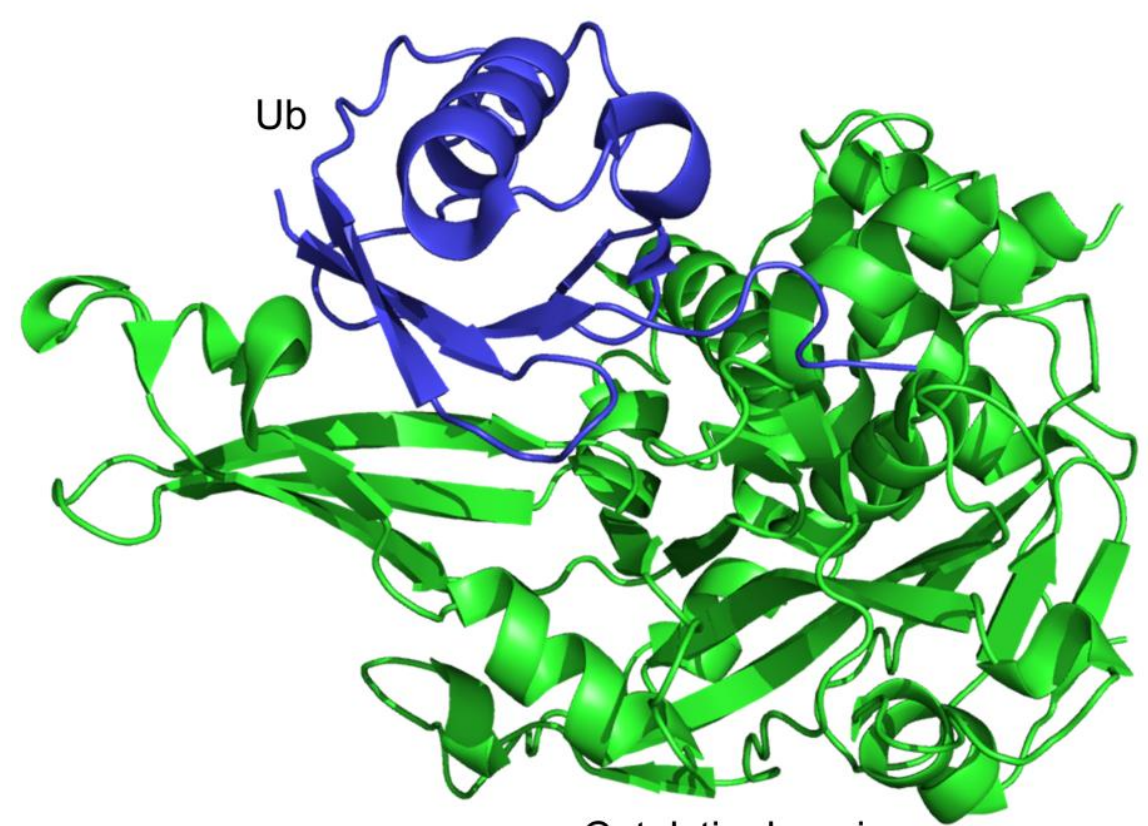

Catalytic domain

(B)

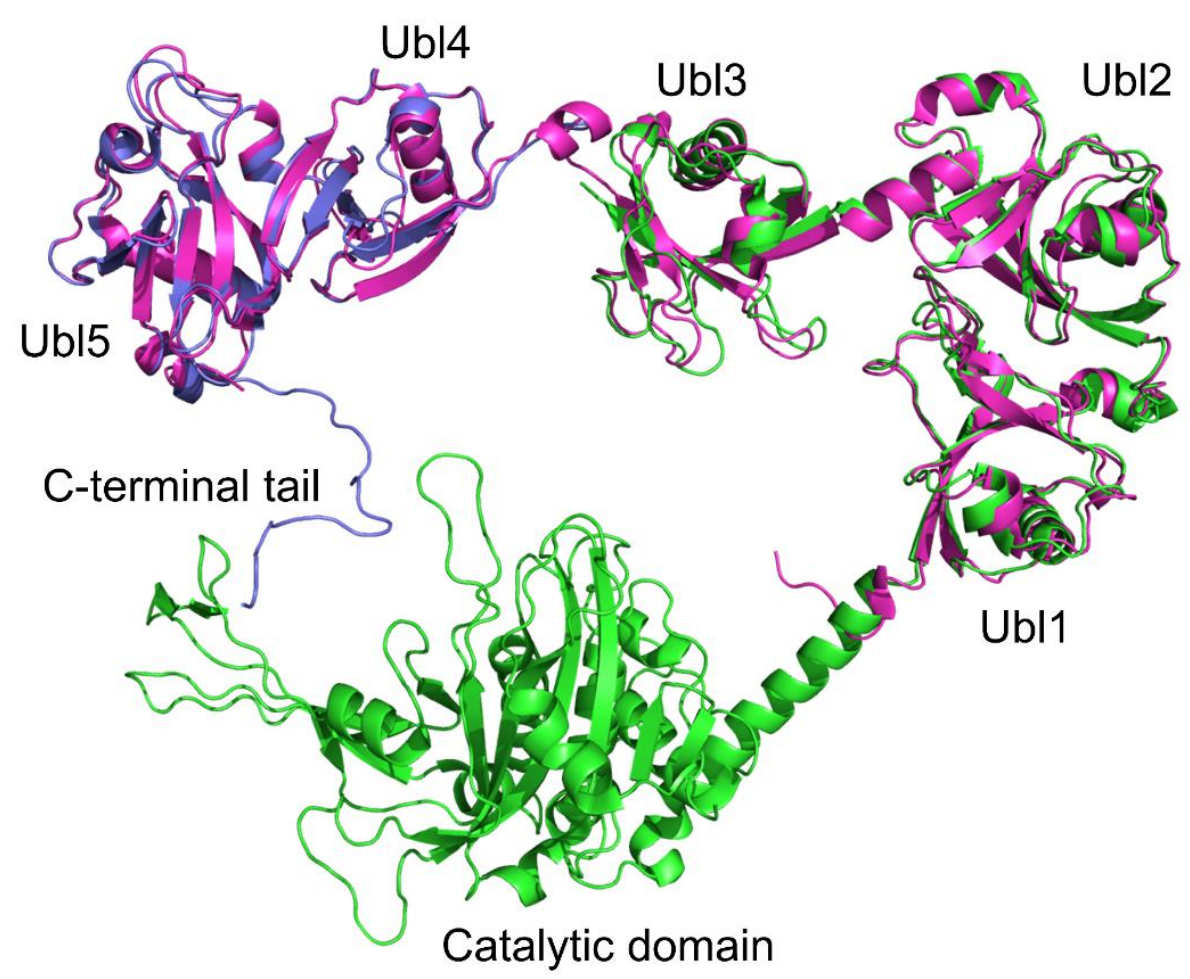

Figure S16. Illustration of the binding mode between Ub and USP7.

(A) Crystal structure of USP7 catalytic domain in complex with ubiquitin (PDB: 5KYC); (B) Superimposed model to illustrate the interaction of USP7 C-terminal tail with catalytic domain. USP7 C-terminal peptide tail interacting with catalytic domain. The superimposed structures of USP7 (green, PDB: 5J7T; red, PDB: 5JTV; purple, PDB: 2YLM). 


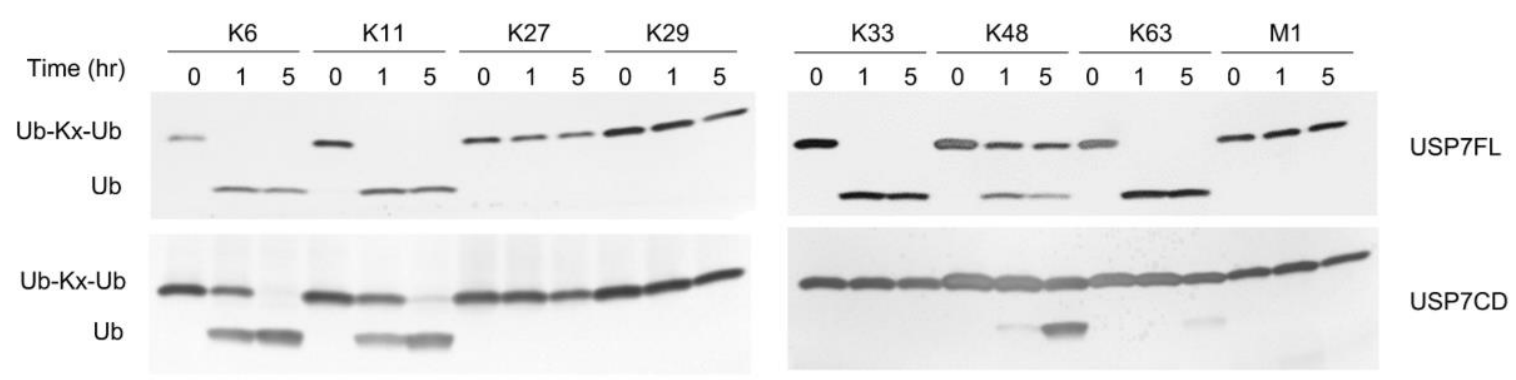

Figure S17. Digestion assay of Ub dimers.

Digestion of USP7FL and USP7CD against 8 Ub dimers. The gels were visualized by silver staining. 


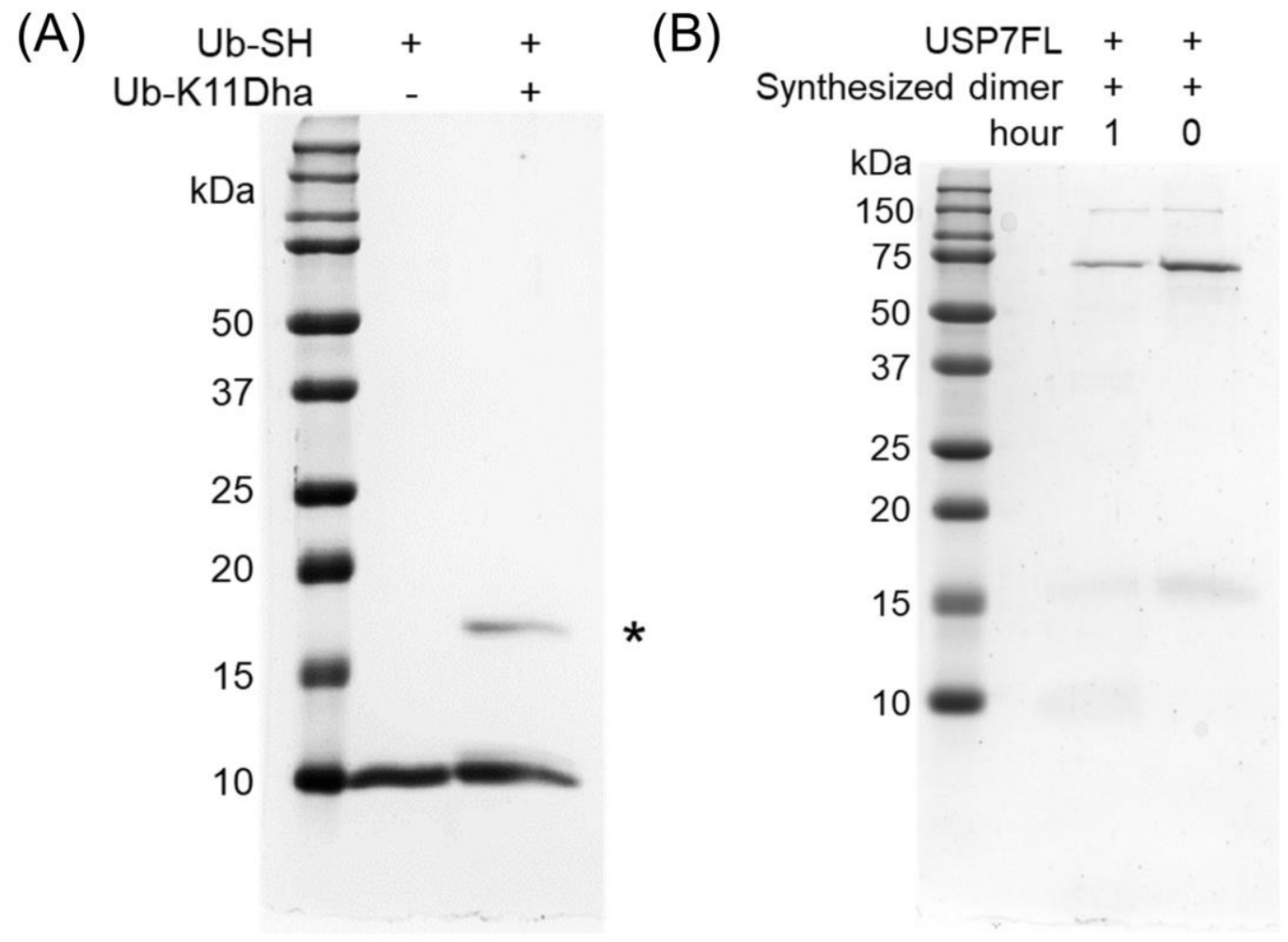

Figure S18. Digestion assay of USP7FL against synthesized K11-linked Ub dimer.

(A) The synthesis of the K11-linked Ub dimer was conducted using Ub-K11Dha ( $3 \mu \mathrm{M})$ and Ub-SH $(6$ $\mu \mathrm{M})$ under native condition. The reaction mixture was analyzed by $15 \%$ SDS-PAGE with instant blue staining. The black asterisk represents the synthesized dimer; (B) Digestion assay of USP7FL was performed in the presence of synthesized K11-linked $\mathrm{Ub}$ dimer at $37^{\circ} \mathrm{C}$ for $1 \mathrm{~h}$. The samples were analyzed by $15 \%$ SDS-PAGE with instant blue staining. 